July 2001 - NREL/TP-500-30032

\title{
Wind Power Plant Monitoring Project Annual Report
}

\author{
Yih-Huei Wan
}

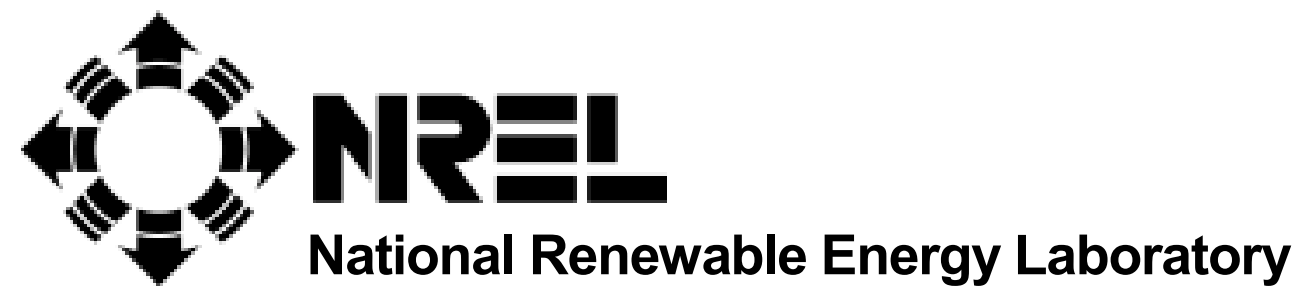

1617 Cole Boulevard

Golden, Colorado 80401-3393

NREL is a U.S. Department of Energy Laboratory

Operated by Midwest Research Institute • Battelle $\bullet$ Bechtel

Contract No. DE-AC36-99-G010337 


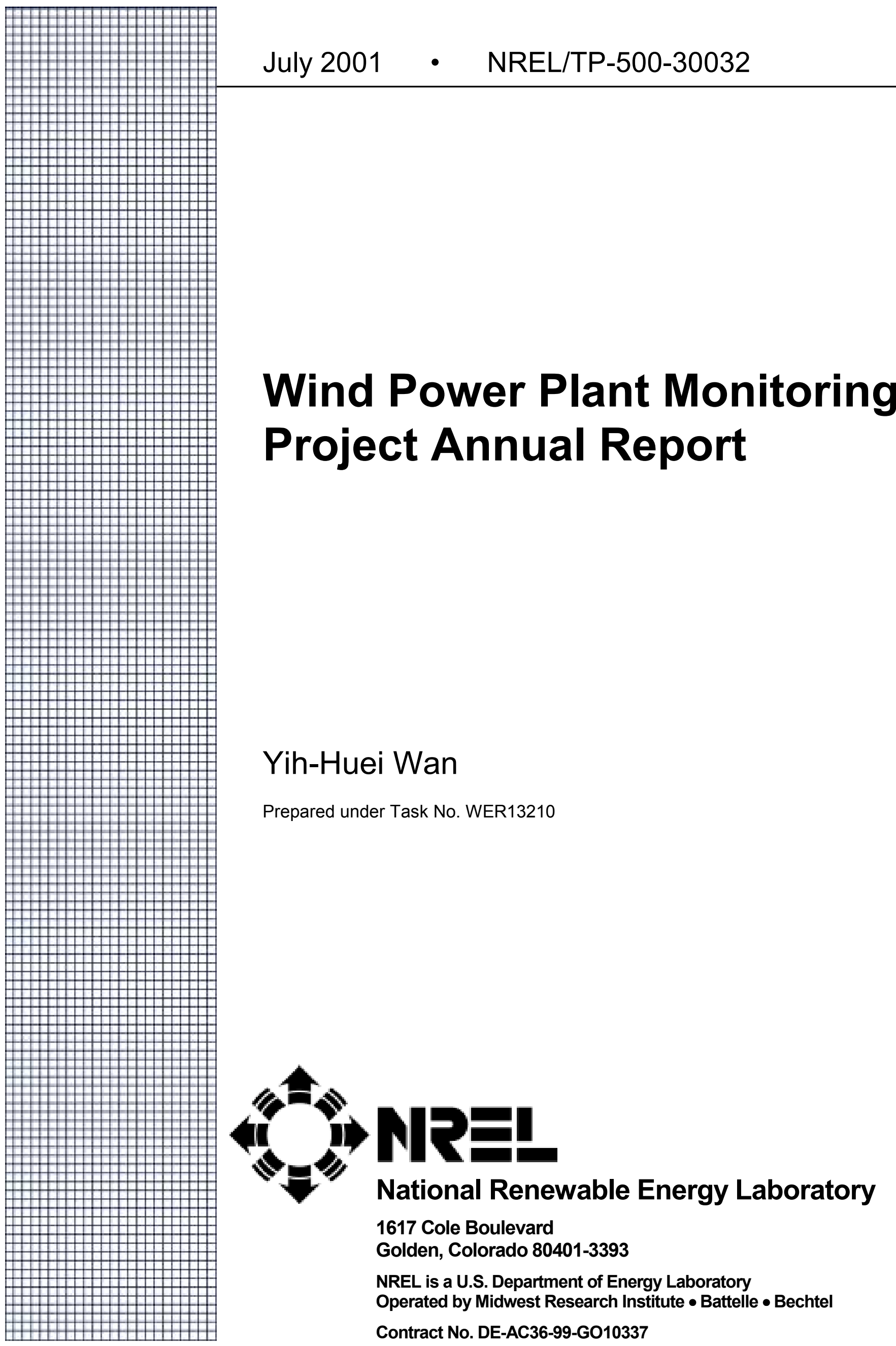




\section{NOTICE}

This report was prepared as an account of work sponsored by an agency of the United States government. Neither the United States government nor any agency thereof, nor any of their employees, makes any warranty, express or implied, or assumes any legal liability or responsibility for the accuracy, completeness, or usefulness of any information, apparatus, product, or process disclosed, or represents that its use would not infringe privately owned rights. Reference herein to any specific commercial product, process, or service by trade name, trademark, manufacturer, or otherwise does not necessarily constitute or imply its endorsement, recommendation, or favoring by the United States government or any agency thereof. The views and opinions of authors expressed herein do not necessarily state or reflect those of the United States government or any agency thereof.

Available electronically at http://www.doe.gov/bridge

Available for a processing fee to U.S. Department of Energy

and its contractors, in paper, from:

U.S. Department of Energy

Office of Scientific and Technical Information

P.O. Box 62

Oak Ridge, TN 37831-0062

phone: 865.576.8401

fax: 865.576.5728

email: reports@adonis.osti.gov

Available for sale to the public, in paper, from:

U.S. Department of Commerce

National Technical Information Service

5285 Port Royal Road

Springfield, VA 22161

phone: 800.553.6847

fax: 703.605.6900

email: orders@ntis.fedworld.gov

online ordering: http://www.ntis.gov/ordering.htm

Printed on paper containing at least $50 \%$ wastepaper, including $20 \%$ postconsumer waste 


\section{Table of Contents}

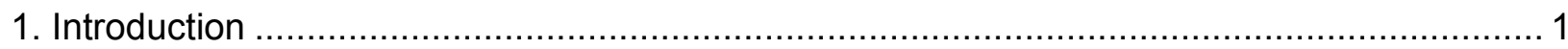

1.1 BACKGROUND

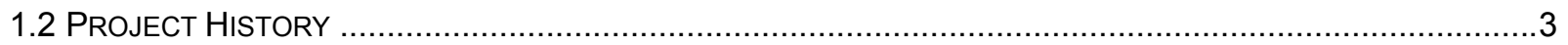

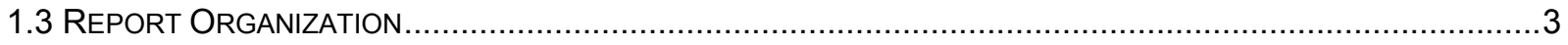

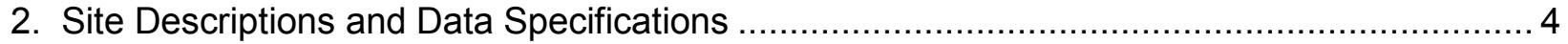

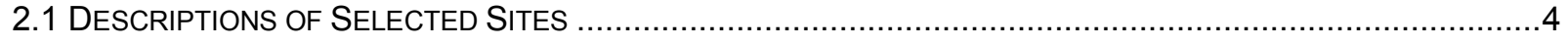

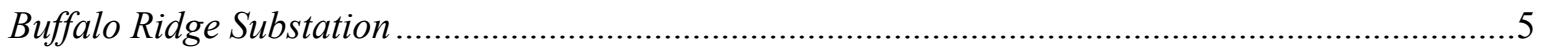

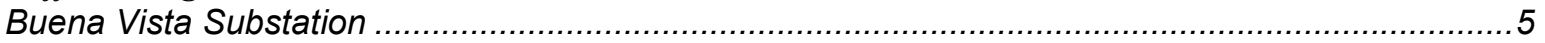

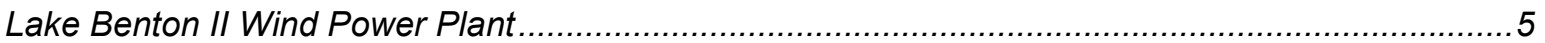

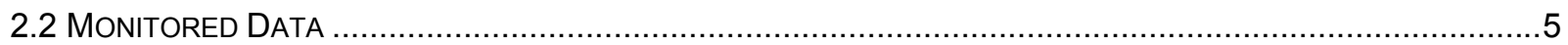

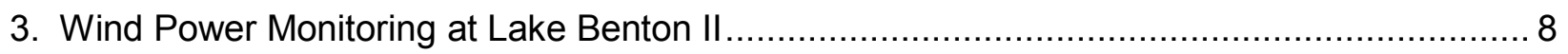

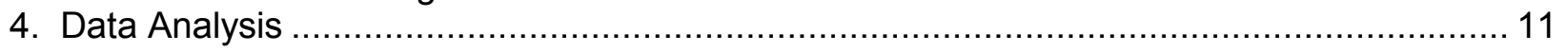

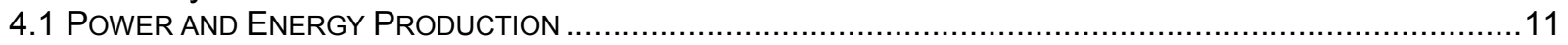

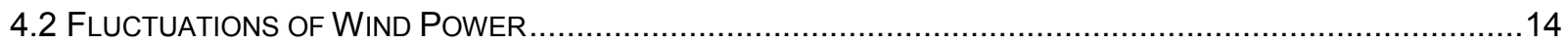

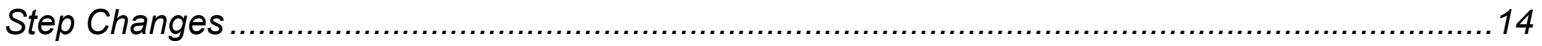

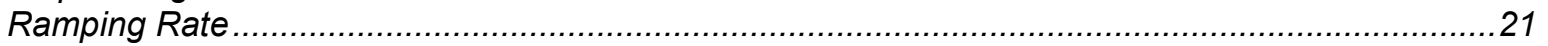

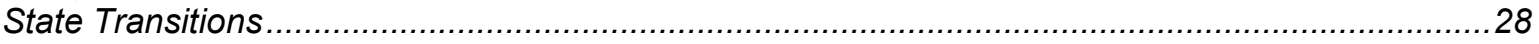

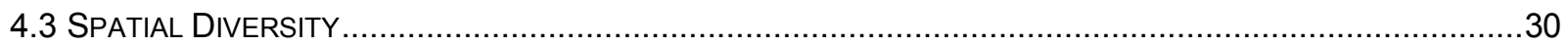

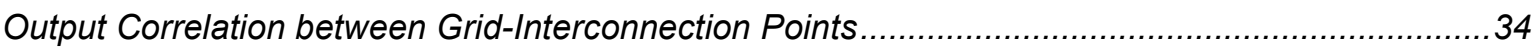

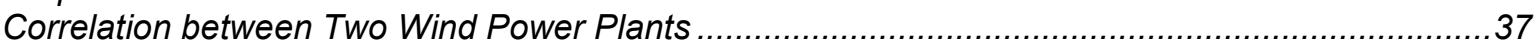

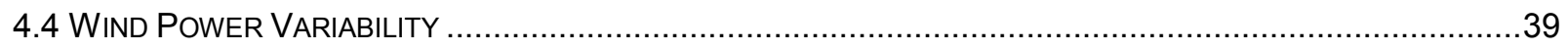

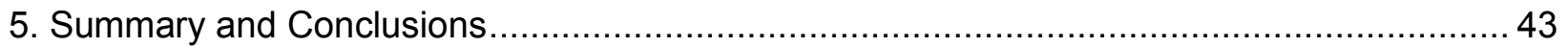




\section{Tables}

Table 4-1. Lake Benton II 1-second and 1-hour Average Peak Power ................................. 13

Table 4-2. Maximum, Average, and Standard Deviation of Lake Benton II Step Changes .... 15

Table 4-3. Average and Standard Deviations of Positive and Negative Step Changes .......... 17

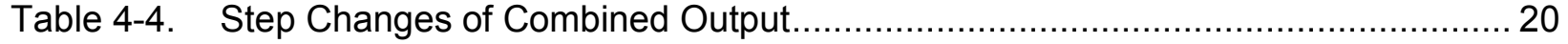

Table 4-5. Ramping Rates (kW/s) Based on 1-Second Power Data................................... 22

Table 4-6. Ramping Rates (kW/min) Based on 1-minute Average Power Data ...................... 25

Table 4-7. State Transition Rates with 1-Second Power Data .............................................. 29

Table 4-8. State Transition Rates with 1-Minute Average Power Data ................................... 30

Table 4-9. Coincident Factors .............................................................................. 33

Table 4-10. Coincident Factors of Lake Benton II and Storm Lake..................................... 34

Table 4-11. Output Power Correlation Coefficients Among Interconnection Points ................. 35

Table 4-12. Correlation coefficient Between Lake Benton II and Storm Lake ......................... 37

Table 4-13. Coefficient of Variability of Wind Speed at Echo............................................. 40

Table 4-14. COV of Wind Speed Cubed, Echo Output, and Lake Benton II Output................. 41

Table 4-15. Individual Grind-Interconnection Points and Wind Power Plant Output COVs ...... 42

Figures

Figure 2-1. Location of selected wind power plants for monitoring ……........................... 4

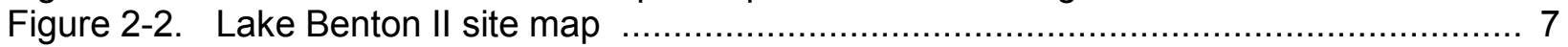

Figure 3-1. Echo interconnection point of Lake Benton II wind power plant ......................... 8

Figure 3-2. Block diagram of Lake Benton II data monitoring setup .................................. 9

Figure 3-3. Three-line diagram of Lake Benton II data monitoring setup …........................ 10

Figure 3-4. Signal flow diagram of Lake Benton II data monitoring setup .......................... 10

Figure 4-1. Monthly power output at Lake Benton II ..................................................... 11

Figure 4-2. Hourly power output profile at Lake Benton II ............................................. 12

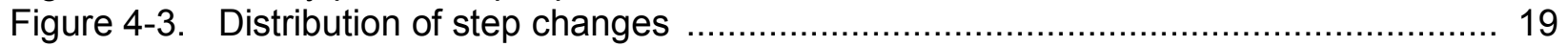

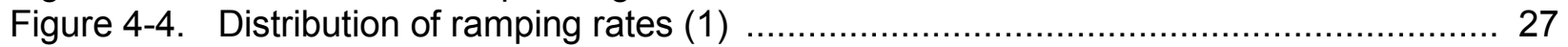

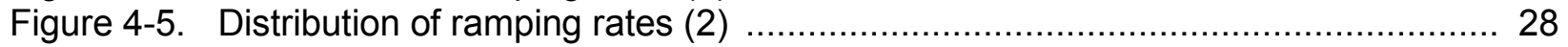

Figure 4-6. Sample daily power output profile ……….............................................. 31

Figure 4-7. Detailed local peak with 1-second data ................................................. 32

Figure 4-8. Output profiles of Lake Benton II and Storm Lake ...................................... 38

Figure 4-9. Another output profile of Lake Benton II and Storm Lake ............................... 39 


\section{Introduction}

This report provides details on the wind power plant monitoring project at the National Wind Technology Center. It describes the project's structure and the data collected, as well as results of data analyses.

In the past 20 years, the application of wind energy has increased steadily in the United States and throughout the world. With continued research and development and improved manufacturing processes, wind turbine performance has improved. More significantly, wind power costs have dropped to the point where, on a cents-per-kilowatt-hour $(\mathrm{kWh})$ basis, they are very close to being competitive with those of traditional fossil-fuel generation. With the aid of various state policies and the emerging green power market, several large- and medium-scale wind power plants with modern wind turbines have been built in the United States in the past few years.

As a result of these developments, more utilities today are seriously examining the wind option.

Nevertheless, some utilities have expressed concern over short-term power fluctuations and their possible effects on the electric power system. Power fluctuations might also affect wind power's participation in the bulk-power market by affecting its ancillary-services requirements in a competitive business environment. Ancillary services are interconnected operations services identified by the U.S. Federal Energy Regulatory Commission (Order No. 888, issued April 24, 1996) as necessary to effect a transfer of electricity between purchasing and selling entities, and which a transmission provider must include in an open-access transmission tariff. They include energy imbalance, operating reserve, reactive power supply and voltage control, regulation and frequency response, and scheduling. Wind power developers and wind plant operators need to know the realistic economic impacts of ancillary services requirements for wind power that are derived from real wind power data. Real wind power data would also allow researchers to investigate the extent of the spatial and temporal diversity of wind power, as well as capacity credit issues. Despite these concerns and the need of using long-term, high-frequency real wind power plant output data to analyze the impacts, no programs have systematically collected such data.

This project was designed to remedy the situation with the following two major objectives:

1. Collect at least 2 years of long-term, high-frequency (1-hertz [Hz]) data from several medium- to large-scale wind power plants with different wind resources, terrain features, and turbine types.

2. Analyze the data for power fluctuations, frequency distribution of wind power (by deriving a probability distribution function of wind power plant output variations), spatial and temporal diversity of wind power, and wind power capacity credit issues.

Results of these analyses can provide data on the potential effects of wind power plants on power system regulation. Such information enables utilities to better understand the regulation requirements for wind power plants and assists utilities in planning and operating the electric grid to integrate wind power into the power system.

The National Renewable Energy Laboratory (NREL) awarded a subcontract to collect wind power data from wind power plants in Minnesota and Iowa. In addition, NREL initiated a separate data-monitoring program at the Lake Benton II (LB II) wind power plant, also in Minnesota. Data were collected on real power, reactive power, three-phase line-to-ground voltages, and wind speed—all at $1 \mathrm{~Hz}$. 


\subsection{Background}

The intermittent nature of the wind resource, together with short-term power fluctuations, are the two principal issues facing a utility with wind power plants in its power grid. Researchers ${ }^{1}$ at NREL, have long recognized that these issues are barriers to utility acceptance of wind power. The utility system operator must maintain a balance between system load and power production to keep the system stable. This includes accommodating random and peak-to-non-peak load variations in the context of customary long-term planning and short-term scheduling practices of utilities. Utilities, wind power plant developers, and operators need to understand the nature of wind power fluctuations and how they affect the electrical power system, as well as to analyze ancillary service requirements with real wind power plant output data.

Furthermore, as the electric sector moves toward restructuring and developing a competitive market for power generation, the attributes of each individual generator will be more closely assessed, as opposed to assessing the whole system. As a result, all generation sources will be examined on a second-to-second and minute-to-minute basis in the context of ancillary services, which can greatly affect the competitiveness of wind power.

Neither the U.S. Department of Energy (DOE) Wind Energy Program nor industry has had the ability to accurately assess wind power's ancillary-services burdens (or benefits) or second-to-second, minute-tominute power fluctuations in a widespread, systematic way. Examination of 1-second power output data sets and synchronized power outputs of individual machines from wind power plants of different size, geography, and wind resource type will allow industry to evaluate the potential ancillary-service impacts and costs that result from power fluctuations. Various approaches such as different control strategies, new turbine designs, and innovative business partnerships with other electric resources have been suggested to mitigate the effects of wind power fluctuations on the power system and on the ancillary service requirement of wind power. This evaluation will facilitate research that examines these approaches. It can also help researchers quantify the benefits of short-term electric storage systems with wind generation.

In addition, these new data will allow researchers to evaluate local micro-siting effects. They will also be able to investigate the correlation statistics between machines to field-test the assumption that the aggregate power variation from a larger number of machines has smaller fluctuations than those from a smaller cluster or single machine (on a percentage basis). If utility loads and incremental-cost data are available, the power outputs can be evaluated for capacity values. The power measurements could also be included in a wind-forecasting development and testing program.

1 For example, Y. Wan and B. Parsons, Factors Relevant to Utility Integration of Intermittent Renewable Technologies, National Renewable Energy Laboratory, NREL/TP-463-4953, 1993. 


\subsection{Project History}

In October 1999, NREL entered a collaborative agreement with Enron Wind Corporation (EWC) to monitor wind power output at the Lake Benton II wind power plant in Minnesota. The plant has 103.5 megawatt (MW) of wind-generating capacity. Monitoring and data-recording equipment were installed at four grid-interconnection points of Lake Benton II. Complete data from this wind power plant have been available since February 2000. The data have been analyzed by staff from NREL and Oak Ridge National Laboratory (ORNL), who focused on the potential effects on ancillary services and costs (as well as other issues associated with the fluctuations of wind power).

In March 2000, NREL awarded a subcontract to Electrotek Concepts, Inc. (Electrotek), to collect power output data from two wind power plants in Minnesota and Iowa. In Minnesota, Electrotek installed data collection and communications equipment at Buffalo Ridge substation of Northern States Power Company (now Xcel Energy). About $220 \mathrm{MW}$ of wind-generating capacity of various designs connect to the Buffalo Ridge substation. In Iowa, Electrotek installed equipment at MidAmerican Energy's Buena Vista substation near Storm Lake. Total wind-generating capacity being monitored at Storm Lake is about $113 \mathrm{MW}$. Electrotek will also record pertinent meteorological data such as wind speed and wind direction at the wind turbine hub height at both locations. Storm Lake data collection began in January 2001. Data collection at Buffalo Ridge started in February 2001.

A fourth wind power plant - Big Spring wind project in Big Spring, Texas - was selected by NREL to be part of the monitored sites. However, during contract negotiations, the bidder withdrew its proposal. To ensure diversity of data, NREL plans to add at least one wind power plant outside the Midwest region in the future.

\subsection{Report Organization}

This report consists of five sections that describe the wind power plant monitoring project, collected data, and preliminary analysis of the data. Section 1 contains the project introduction and background information. Section 2 provides information on the selected wind power plant sites and the specifications for data collected for this project. Section 3 describes in detail NREL's monitoring of Lake Benton II wind power plant. Section 4 presents the first 12 months of data, including statistics and analysis. Section 5 summarizes some prominent features of the data set related to wind power fluctuations. 


\section{Site Descriptions and Data Specifications}

Before selecting sites to monitor, NREL decided that the minimum installed wind-generating capacity for any participating plant should be $15 \mathrm{MW}$, thus ensuring that the collected data would provide realistic information about utility-scale wind power plants. When determining actual wind power plants, researchers also considered the geography and terrain of the each site in order to maximize spatial diversity of the collected wind power data.

\subsection{Descriptions of Selected Sites}

Three wind power plant sites were selected for output monitoring in this project: the Buffalo Ridge substation, the Buena Vista substation, and the Lake Benton II wind power plant. The Buffalo Ridge substation is located near Lake Benton, in Pipestone county, Minnesota. It is part of Northern States Power Company's (now part of Xcel Energy) 115-kilovolt $(\mathrm{kV})$ transmission system. The Buena Vista substation is located near Storm Lake, in Buena Vista county, Iowa. The Lake Benton II wind power plant is one of five wind power plants that feed into the Buffalo Ridge substation. Figure 2-1 shows a map of Minnesota and Iowa and the locations of Lake Benton and Storm Lake.

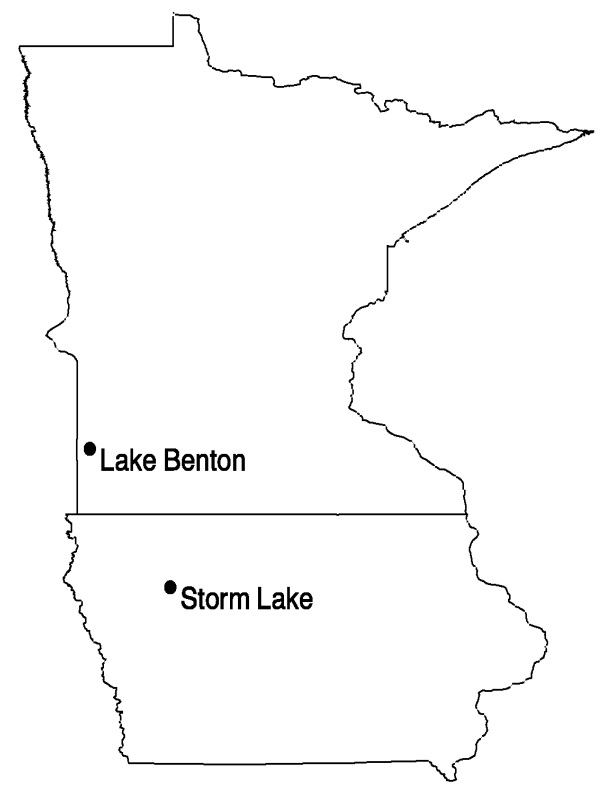

Figure 2-1. Locations of selected wind power plants for monitoring 


\section{Buffalo Ridge Substation}

The Buffalo Ridge substation is located in southwestern Minnesota in the state's premier wind resource area known as Buffalo Ridge. Storm-driven winds occur as a result of the passage of weather fronts throughout the year. The wind resource is better in winter and early spring as the weather systems are more intense and numerous during that time of the year.

Several wind power plants of varying size are in this geographically diverse area. Most are connected to the Buffalo Ridge substation, which is connected to the $115-\mathrm{kV}$ transmission system in that area. Total wind-generating capacity directly connected to the substation is about $220 \mathrm{MW}$. Most of the wind turbines at this area are 750-kW turbines (Z50) made by Zond Systems, Inc. There are also a small number of Micon 750-kW and Vestas 660-kW turbines.

\section{Buena Vista Substation}

The Storm Lake wind power plant is in northwestern Iowa near Storm Lake. The total installed windgenerating capacity at this site is $196.5 \mathrm{MW}$, generated by 262 Zond turbines. Of the power plant's generating capacity, $113 \mathrm{MW}$ are connected to MidAmerican Energy's Buena Vista substation, where the monitoring equipment is installed. The substation is part of the $161-\mathrm{kV}$ transmission system in this region. The wind resource here is similar to that of Buffalo Ridge, with weather fronts responsible for much of the energy resource.

\section{Lake Benton II Wind Power Plant}

The Lake Benton II wind power plant is part of the wind-generating capacity installed in the Buffalo Ridge area. Located near the town of Ruthton, Minnesota, it consists of 138 Zond Z-50, 750-kW wind turbines equipped with reactive power controls. Total installed capacity of the Lake Benton II plant is 103.5 MW. The wind turbines are connected to the Northern States Power Buffalo Ridge substation through four $34.5-\mathrm{kV}$ feeders. The four interconnection points are designated as Delta, Echo, Foxtrot, and Golf. 30 turbines are connected to Delta, 39 to Echo, 14 to Foxtrot, and 55 to Golf. Power-monitoring equipment is installed at all four grid-interconnection points. Figure 2-2 shows the locations of the138 wind turbines at Lake Benton II.

\subsection{Monitored Data}

The data recorded from the selected wind power plants include real power, reactive power, and feeder voltage per second at the grid-interconnection point. Representative wind speeds and directions, temperature, and barometric pressure are also recorded. All data records have identification (ID) indicating the reporting wind power plants. Every record is date- and time-stamped with Julian day, hour, minute, and second for aggregation with other data collected for this project. Table 2-1 lists the recorded data. 
Table 2-1. Specifications for Monitored Wind Power Plant Data

\begin{tabular}{|c|c|c|c|}
\hline Variables & Units & Resolution & Comments \\
\hline ID & Device & & \\
\hline Real power & $\mathrm{kW}$ & 1 second & \\
\hline Reactive power & kVAR & 1 second & \\
\hline $\begin{array}{l}\text { Feed or } \\
\text { interconnection point } \\
\text { voltage }\end{array}$ & $\mathrm{kV}$ & 1 second & $\begin{array}{l}\text { Three-phase line-to-line or line-to-ground } \\
\text { voltage }\end{array}$ \\
\hline Wind speed & meters/second & 30 seconds & $\begin{array}{l}\text { Recorded at hub height or existing on- } \\
\text { site meteorological towers }\end{array}$ \\
\hline Wind direction & $\begin{array}{l}\text { Degrees (from true } \\
\text { north) }\end{array}$ & 30 seconds & \\
\hline Ambient temperature & Degrees C & 10 minutes & \\
\hline Local air pressure & Kilopascals & 10 minutes & \\
\hline Time of day & hh:mm:ss & 1 second & All records time synched \\
\hline Date & Julian days & 1 second & All records time synched \\
\hline
\end{tabular}

Data are archived at the National Wind Technology Center. For added security, two separate data sets are maintained in two independent computer systems. All measurement instruments used for monitoring are recalibrated annually. For the duration of the project, clocks at the monitoring sites are resynchronized at least once every three months. 


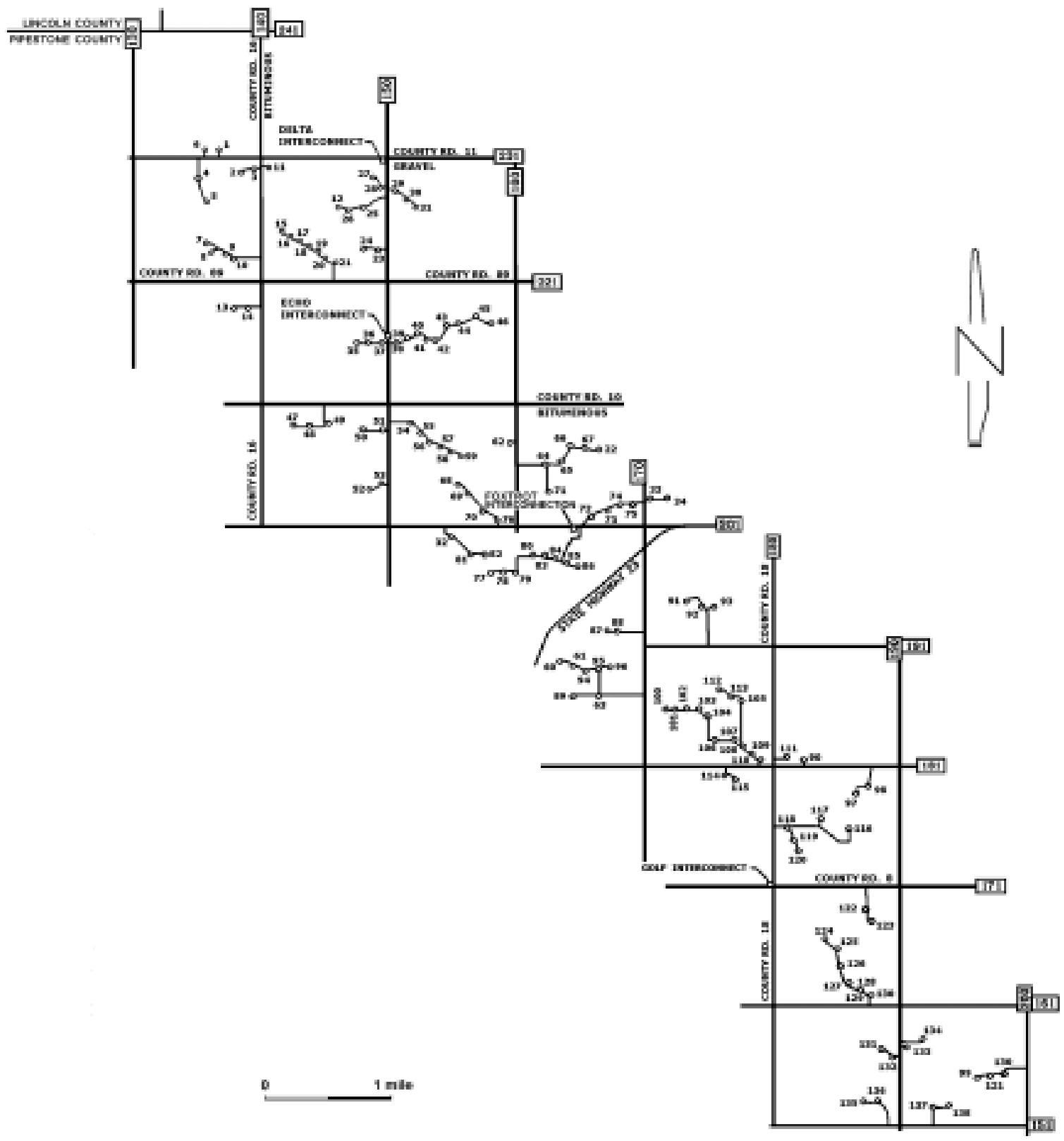

Figure 2-2. Lake Benton II site map 


\section{Wind Power Monitoring at Lake Benton II}

NREL began monitoring Lake Benton II in November 1999 after reaching an agreement with Enron Wind Corporation in October 1999. NWTC technicians installed data-recording equipment at the Delta and Echo interconnection points first to test the design of the monitoring and communication systems. Installation of the monitoring equipment at the other two grid-interconnection points was completed by February 2000.

Figure 3-1 is a view of Echo grid-interconnection point. It shows utility bus work, circuit breaker, switches, voltage regulators, voltage and current transformers, and a small metal building inside a chainlink fence. All four interconnection points share the same design. The metal building houses EWC's metering and control equipment and NREL's monitoring equipment. The local telephone company installed underground phone lines into the metal building for data transmission to NREL.

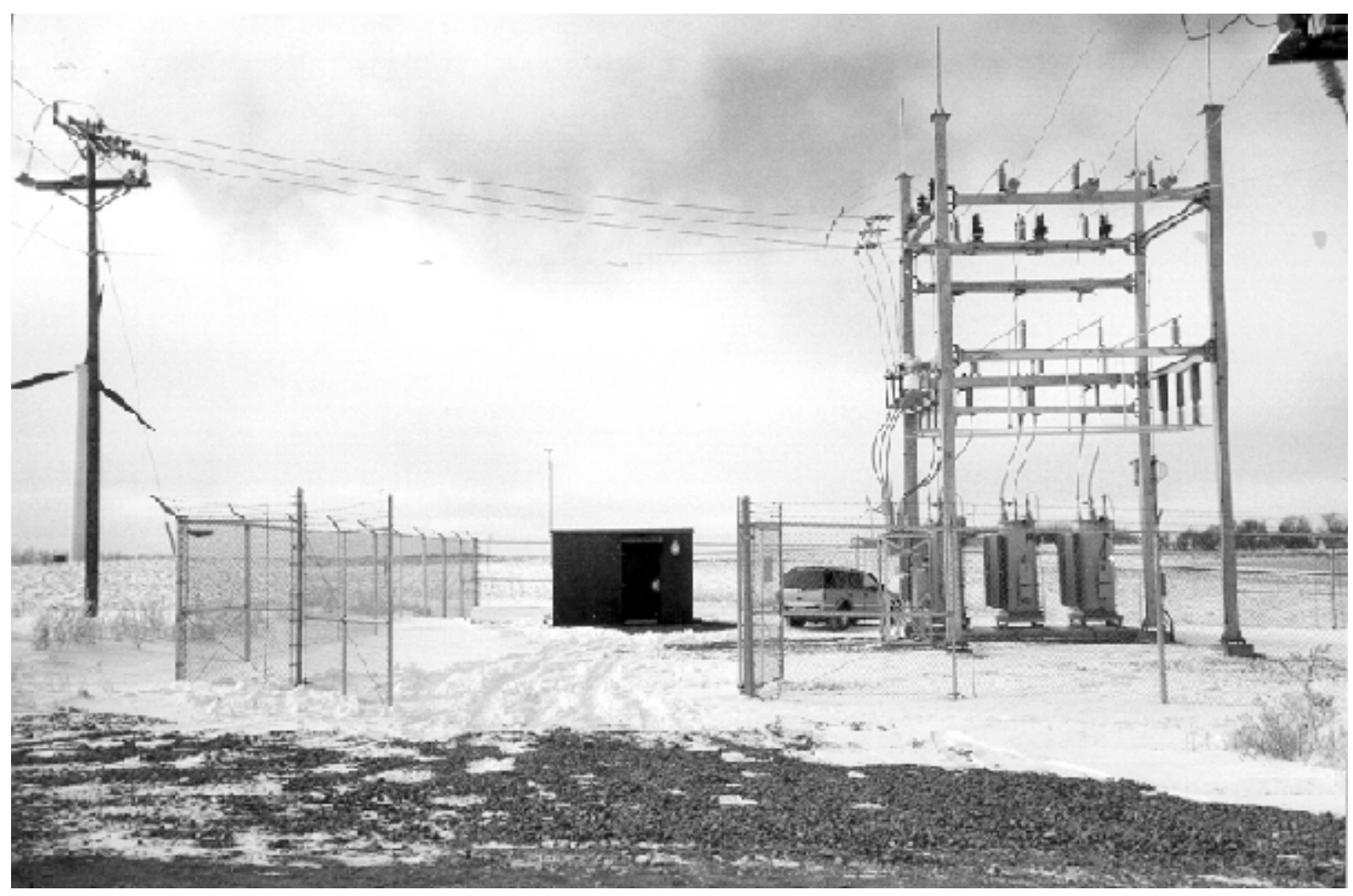

Figure 3-1. Echo interconnection point of Lake Benton II wind power plant

- The monitoring equipment used by NREL at each interconnection point includes One three-element watt/VAR transducer

- One three-element voltage transducer

- One data logger with external modem

- One uninterruptible power supply (UPS)

- One test switch

- One personal computer with Iomega external (or internal) ZIPTM 100 drive.

The equipment was chosen based on NREL staff's previous experience and economic considerations. To collect wind speed information, a simple cup-type anemometer (NRG Max40) was installed on top of a 
5-foot antenna pole atop the metal building at the Echo interconnection point (Figure 3-1). Because of the location and height of the anemometer, its wind speed data does not represent true wind resource data for the site. Nevertheless, its data provide some indication of the available wind resource and a good indication of the wind speed trend, both of which are useful in analyzing the power output data. EWC agreed to provide NREL with 10-minute average wind speed data collected from two of its five on-site meteorological towers.

Voltage and current signals are provided by potential transformers and current transformers owned by EWC. Real and reactive power are calculated from voltage and current signals and stored temporary in a 2-MB random-access memory (RAM) bank in the datalogger. The RAM bank can store about 36 hours of data. When the memory is full, new data will overwrite the old data. Telephone lines are dedicated to data transmission only, and they connect directly to the datalogger modem. Figure 3-2 provides a schematic of the power-monitoring equipment at each interconnection point. Figures 3-3 and 3-4 are detailed three-line circuit diagrams of the monitoring equipment for Lake Benton II.

Data are downloaded to the NWTC's server every day via telephone and modem. As a backup, the data are written daily to on-site ZIPTM disks. EWC field personnel replace the ZIP ${ }^{\mathrm{TM}}$ disks with blank ones for NREL every two weeks and mail the disks containing data to the NWTC. At NREL's request, EWC field personnel will also inspect and report the status of monitoring equipment and, if possible, perform limited troubleshooting. With this arrangement, NREL has been able to achieve an overall data recovery rate of $98 \%$. So far, missing data has been the result of equipment failures (damaged by lightning), phone line outages, and computer glitches.

Electrotek Concepts, Inc., uses a different approach to data-recording. Its performance will be compared to that of NREL's data-recording system. The results of the comparison will be taken into consideration when determining which monitoring equipment to use in the future.

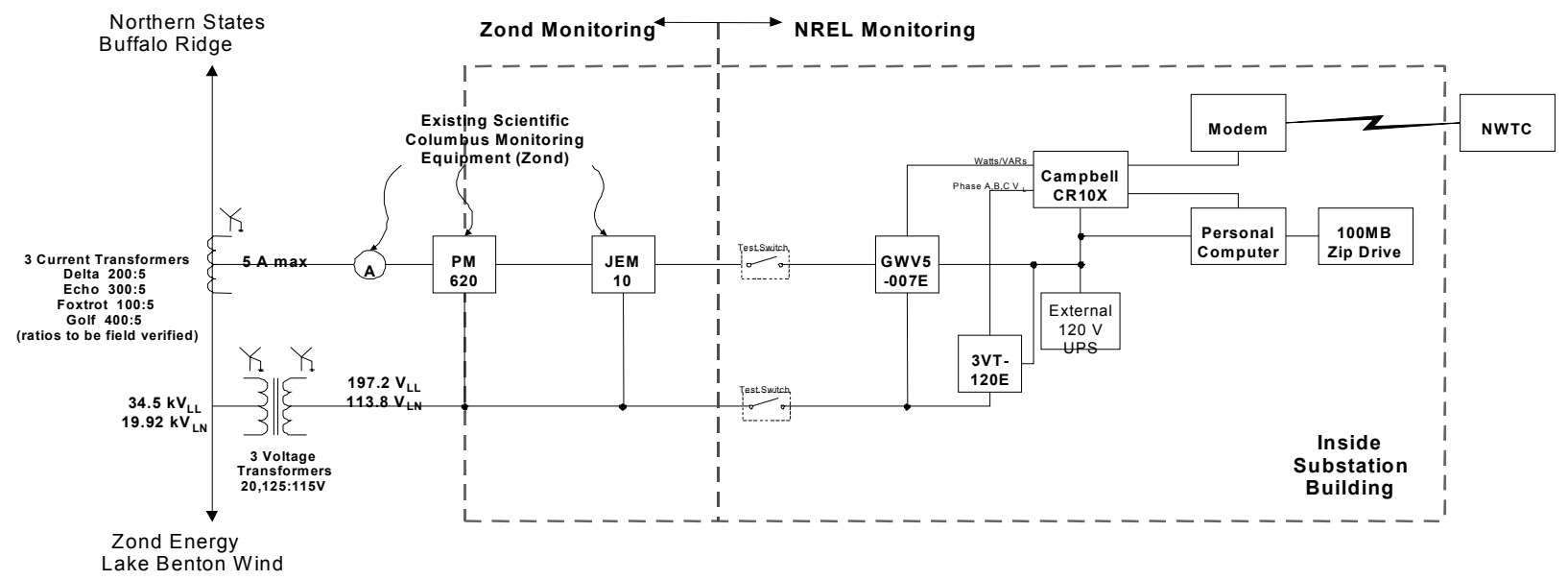

NREL-provided equipment

Ohio Semitronics GWV5-007E watt/VAR Transducer Ohio Semitronics 3VT-120E 3-Phase Voltage Transducer

Campell Scientific CR10X Data Logger/Power Supply/UPS

Data Logger

Data Storage and Transmission Equipment

Test Switches (10-pole, Milbank)

Figure 3-2. Block diagram of Lake Benton II data monitoring setup 


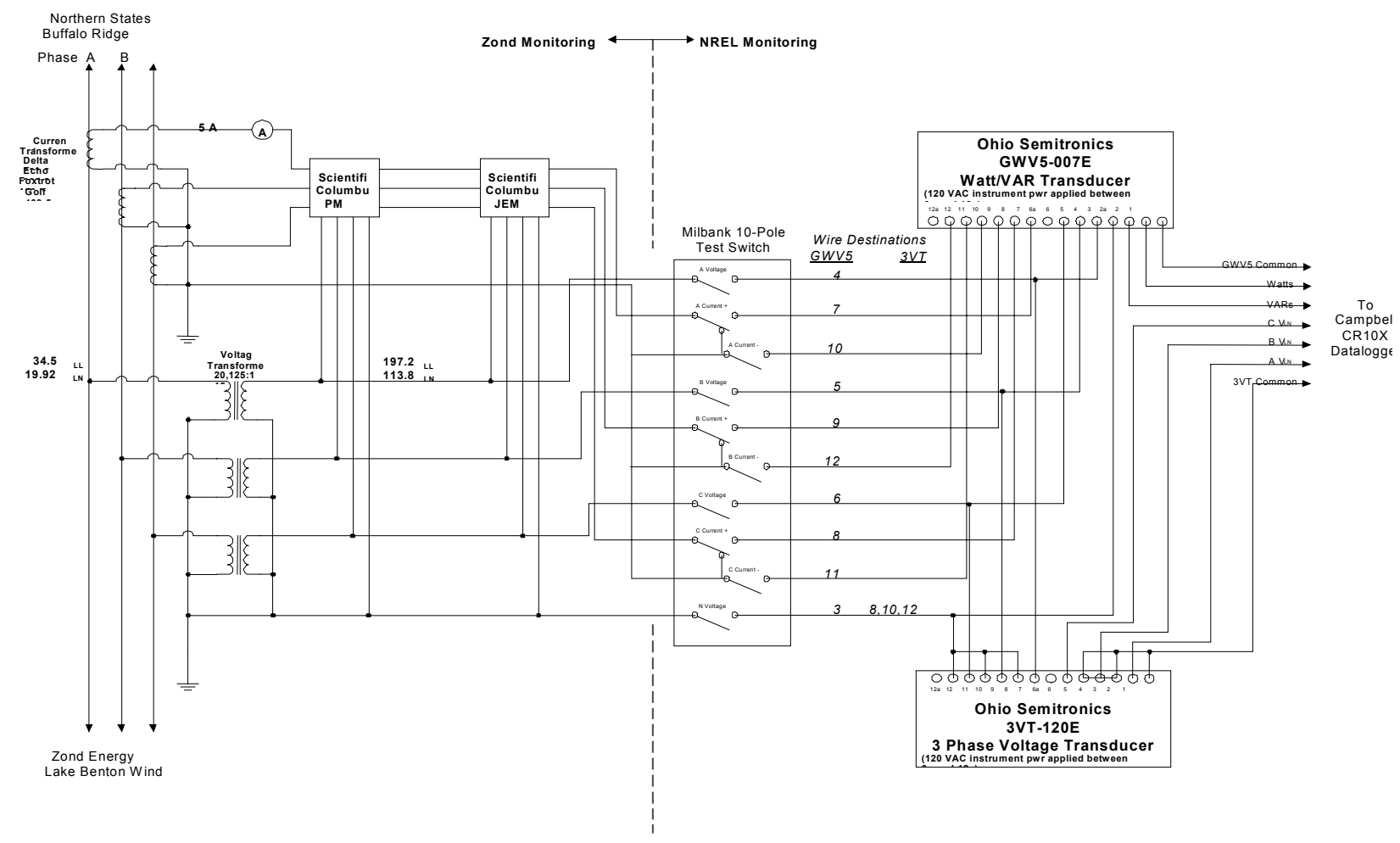

Figure 3-3. Three-line circuit diagram of Lake Benton II data monitoring setup

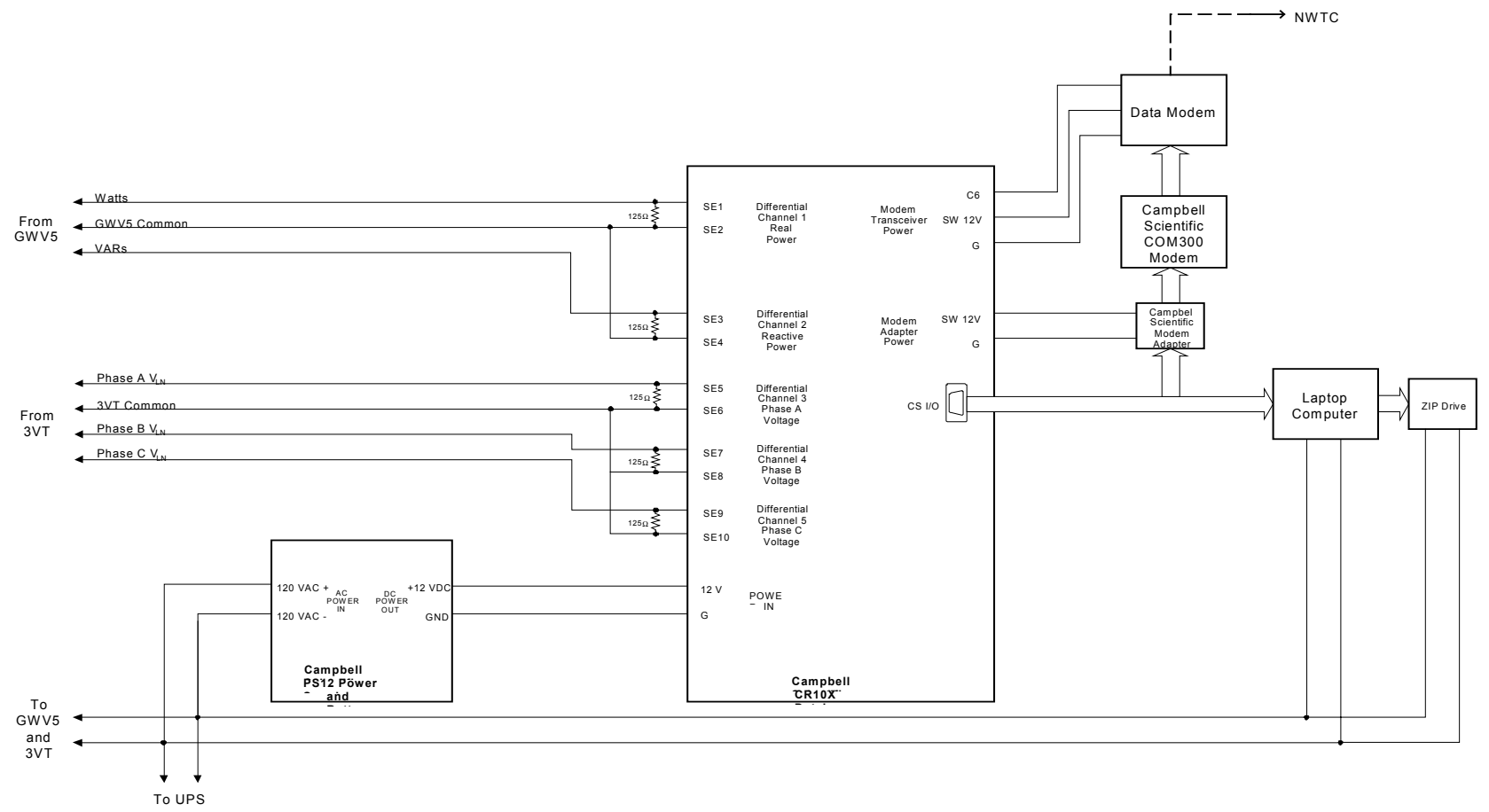

Figure 3-4. Signal flow diagram of Lake Benton II data monitoring setup 


\section{Data Analysis}

Oak Ridge National Laboratory staff will use the data to analyze wind power plant ancillary services requirements. The data will be used to analyze power fluctuations from the wind power plant and to study how spatial and temporal diversity affect power outputs from single and multiple wind power plants. NREL's analysis will also attempt to detect any distinctive power output patterns (daily and seasonally) and trends from multiple wind power plants. Data included in this report are 12 months of real power and wind speed data from Lake Benton II (from February 2000 to January 2001) and one month of real power data from Storm Lake.

This section begins with a description of the energy production at Lake Benton II to give an overview of the wind power plant performance. It is followed by detailed analysis of power fluctuations. Transition rates of wind power from one level to another are also calculated to show the wind power persistency. This section concludes with an investigation of wind power spatial diversity and its effect on wind power variability.

\subsection{Power and Energy Production}

Power production at the Lake Benton II wind power plant is higher during winter than during summer. Storm Lake should have a similar pattern. Figure 4-1 shows monthly production (in megawatt-hours [MWh]) at Lake Benton II. Monthly power production varies significantly; the highest monthly production is more than twice the lowest monthly production. Generally, wind resources during the months of July and August are less favorable for power generation than other months. Low production in July was partially the result of monitoring equipment failure, which caused data losses. The many forced outages at the Lake Benton II plant during July also had an effect on production.

Lake Benton II Monthly Production

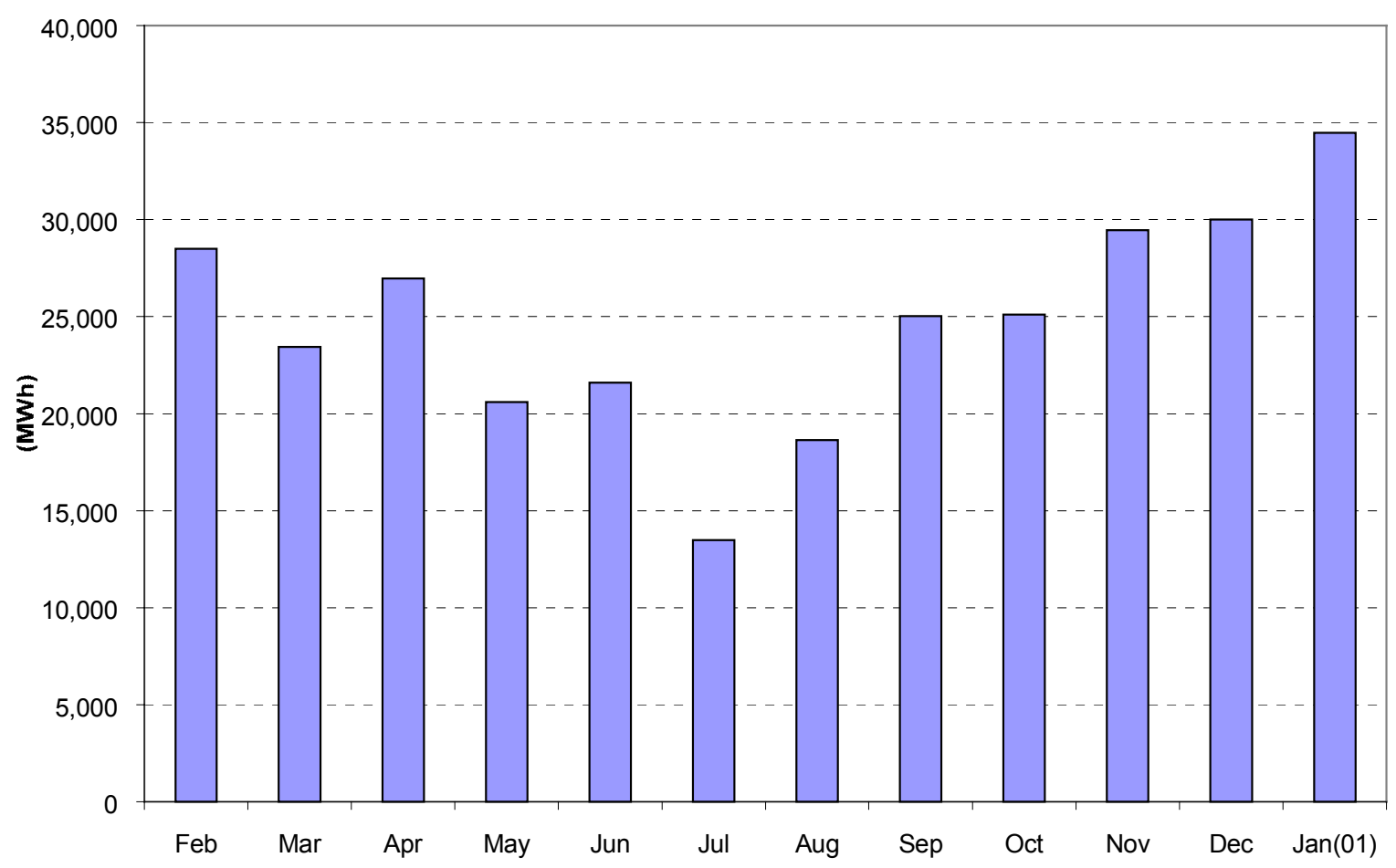

Figure 4-1. Monthly production 
Figure 4-2 shows Lake Benton II average annual hourly power production superimposed with June hourly pattern. Overall the peak hourly production occurs in the early morning hours; a secondary peak occurs around noon. Summer production shows a different hourly pattern represented by the June hourly profile. A weak afternoon peak is evident, but it is not well-defined. Although other summer months appear to have a slightly different hourly pattern than that in June, their differences are not very prominent.

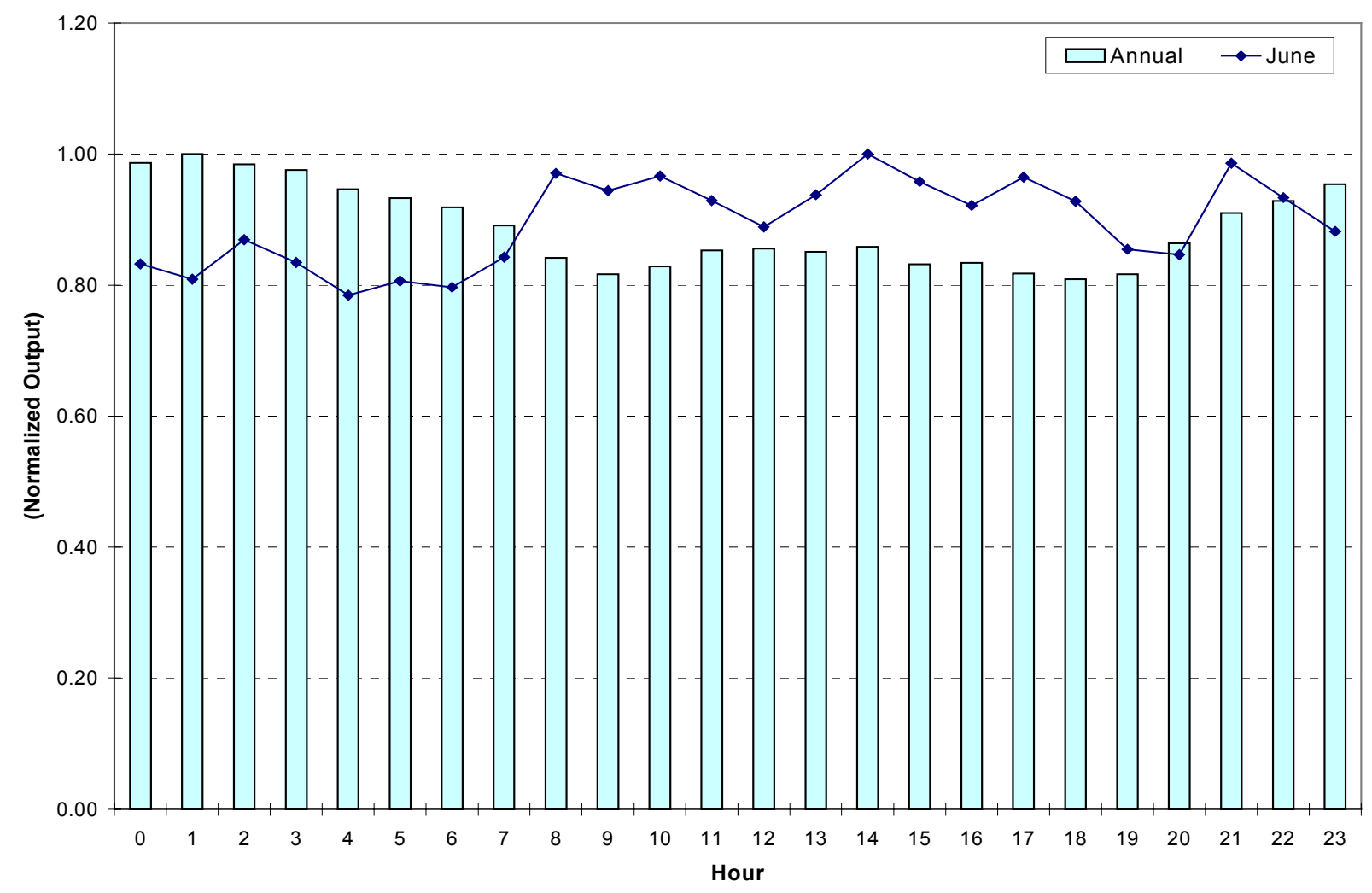

Figure 4-2. Hourly power output profile at Lake Benton II

Table 4-1 shows monthly peak power of four grid-interconnection points and Lake Benton II for three different averaging periods (1-second, 1-minute, and 1-hour). Also included is the coincident factor (CF, in the right-hand column), defined as the ratio of peak power at LB II to the sum of individual peaks at four grid-interconnection points. The turbines at the site are spread out over an area about 7 miles by 9 miles. Because wind speed differs at each individual turbine, not all turbines produce the same amount of power at any given moment. By examining the relationship between each individual gridinterconnection point at peak power and the wind power plant peak power, we can estimate the spatial diversity at Lake Benton II. If there were no spatial diversity, all turbines would produce the same amount of power and the coincident factor would be 1 . In section 4.3, we will discuss spatial diversity in more detail. 
Table 4-1. Lake Benton II 1-second and 1-hour Average Peak Power

\begin{tabular}{lrrrccr}
\hline \multicolumn{1}{c}{ Month } & \multicolumn{7}{c}{ 1-second Peak Power (kW) } \\
\hline \multirow{2}{*}{ February } & Delta & Echo & Foxtrot & Golf & Lake Benton II & CF \\
March & 22,540 & 29,410 & 10,620 & 41,370 & 101,880 & 0.980 \\
April & 22,470 & 29,390 & 10,650 & 40,500 & 100,210 & 0.973 \\
May & 22,540 & 28,070 & 10,680 & 39,750 & 98,670 & 0.977 \\
June & 21,560 & 27,850 & 9,870 & 38,310 & 94,610 & 0.969 \\
July & 21,390 & 27,720 & 9,890 & 39,240 & 92,860 & 0.945 \\
August & 21,440 & 27,590 & 10,580 & 36,730 & 94,410 & 0.980 \\
September & 22,600 & 26,720 & 9,620 & 38,880 & 90,950 & 0.949 \\
October & 21,090 & 29,240 & 10,500 & 40,280 & 98,530 & 0.974 \\
November & 20,780 & 29,050 & 10,630 & 40,680 & 100,110 & 0.990 \\
December & 21,310 & 28,880 & 10,570 & 40,900 & 99,530 & 0.979 \\
January (01) & 21,880 & 28,720 & 10,660 & 41,420 & 100,740 & 0.981 \\
\hline
\end{tabular}

\begin{tabular}{lrrrrcr}
\hline \multicolumn{1}{c}{ Month } & \multicolumn{5}{c}{ 1-minute Peak Power (kW) } \\
\hline February & Delta & Echo & Foxtrot & Golf & Lake Benton II & CF \\
March & 22,138 & 28,708 & 10,442 & 40,642 & 101,143 & 0.992 \\
April & 22,096 & 28,810 & 10,390 & 40,011 & 99,817 & 0.985 \\
May & 22,148 & 27,598 & 10,412 & 39,113 & 97,866 & 0.986 \\
June & 21,314 & 27,537 & 9,669 & 37,596 & 93,746 & 0.975 \\
July & 21,078 & 26,693 & 9,616 & 38,555 & 89,744 & 0.935 \\
August & 20,722 & 27,132 & 10,334 & 35,945 & 92,692 & 0.985 \\
September & 21,332 & 26,260 & 9,461 & 38,386 & 89,126 & 0.944 \\
October & 20,753 & 28,063 & 10,138 & 40,050 & 97,905 & 0.977 \\
November & 20,483 & 28,642 & 10,334 & 40,114 & 98,601 & 0.980 \\
December & 20,974 & 28,435 & 10,313 & 40,151 & 98,589 & 0.987 \\
January (01) & 21,471 & 28,479 & 10,355 & 40,275 & 99,537 & 0.990 \\
\hline
\end{tabular}


Table 4-1. (continued) Lake Benton II 1-second and 1-hour Average Peak Power

\begin{tabular}{lrrrrrr}
\hline \multicolumn{1}{c}{ Monthly } & \multicolumn{5}{c}{ Hourly Peak Power (kW) } \\
\hline & Delta & Echo & Foxtrot & Golf & Lake Benton II & CF \\
February & 21,996 & 28,356 & 10,403 & 40,240 & 99,125 & 0.981 \\
March & 21,974 & 28,604 & 10,124 & 39,540 & 98,677 & 0.984 \\
April & 22,083 & 27,455 & 10,373 & 38,807 & 96,470 & 0.977 \\
May & 20,698 & 27,470 & 9,565 & 36,627 & 92,018 & 0.975 \\
June & 19,855 & 25,521 & 9,466 & 36,392 & 86,975 & 0.953 \\
July & 19,299 & 24,992 & 10,007 & 34,378 & 86,630 & 0.977 \\
August & 18,840 & 25,431 & 8,722 & 37,132 & 87,133 & 0.967 \\
September & 20,322 & 26,907 & 10,017 & 39,217 & 94,444 & 0.979 \\
October & 20,665 & 28,620 & 9,832 & 39,293 & 96,451 & 0.980 \\
November & 20,330 & 28,360 & 10,286 & 39,278 & 98,139 & 0.999 \\
December & 20,859 & 28,224 & 10,154 & 39,613 & 97,658 & 0.988 \\
January (01) & 21,339 & 28,444 & 10,340 & 40,176 & 99,150 & 0.989 \\
\hline
\end{tabular}

\subsection{Fluctuations of Wind Power}

Several measures are used to examine power fluctuations at the LB II wind power plant. Simple statistics and distribution regarding maximum step changes (power level differences between consecutive time steps) and ramping rates (either up or down, caused by the wind picking up or dying down) provide more insight into the nature of the wind power fluctuations.

\section{Step Changes}

The differences in output power levels between consecutive time steps indicate wind power persistency. To quantify the behavior of the wind resource, we calculated the maximum step changes in both positive and negative directions and their means and standard deviations, for three time steps (1-second, 1-minute, and 1-hour, Table 4-2). To focus on only the maximum power changes caused by decreasing or increasing wind speed, we screened the recorded data stream to eliminate power changes caused by forced or controlled outages and startups. To isolate these "artificial" power drops, we excluded those large power drops (to zero or a substantially lower value within 2 seconds) without a corresponding wind speed decrease. In a similar fashion, large power increases from zero or a very low level without corresponding wind speed increases were also excluded. However, this extra step may not totally eliminate power changes from forced outages or planned events, because sudden, significant power drops that do not decrease output power to zero (or a smaller value) will not be detected by such an algorithm. 
It is clear that, for short periods, the step changes are very small. The maximum increase in power is $4,430 \mathrm{~kW}$, or $4.3 \%$ of the nameplate capacity (in 1-second increments), during this 12 -month period. For 1 -minute increments, the maximum increase in power is $11,541 \mathrm{~kW}$, or $11 \%$ of the nameplate capacity, which is equivalent to a sustained ramping-up rate of $192 \mathrm{~kW}$ per second, or $0.2 \%$ of the rated power per second. The maximum 1-second step drop is $7,590 \mathrm{~kW}$, or $7.3 \%$ of the nameplate capacity. For the same period, the maximum 1 -minute step drop is $14,448 \mathrm{~kW}$, or $14.0 \%$ of the nameplate capacity. This is equivalent to a sustained ramping-down rate of $241 \mathrm{~kW} / \mathrm{s}$, which is much smaller than the maximum 1second step change value.

Table 4-2. Maximum, Average, and Standard Deviation of Lake Benton II Step Changes

\begin{tabular}{|c|c|c|c|c|c|c|c|c|}
\hline \multirow[t]{2}{*}{ Month } & \multicolumn{4}{|c|}{ 1-second power (kW) } & \multicolumn{4}{|c|}{ 1-minute average power $(\mathrm{kW})$} \\
\hline & $\begin{array}{c}\text { Max. } \\
\text { Increase }\end{array}$ & $\begin{array}{c}\text { Max. } \\
\text { Decrease }\end{array}$ & Mean & Stdev. & $\begin{array}{c}\text { Max. } \\
\text { Increase }\end{array}$ & $\begin{array}{c}\text { Max } \\
\text { Decrease }\end{array}$ & Mean & Stdev. \\
\hline February & 1,950 & $-1,980$ & 0 & 194 & 4,969 & $-5,492$ & -1 & 1,091 \\
\hline March & 1,870 & $-2,627$ & 0 & 194 & 7,266 & $-7,957$ & -2 & 1,711 \\
\hline April & 3,663 & $-4,837$ & 0 & 212 & 11,541 & $-13,852$ & 0 & 1,776 \\
\hline May & 2,296 & $-5,241$ & 0 & 191 & 9,661 & $-7,846$ & 0 & 1,298 \\
\hline June & 4,430 & $-7,590$ & 0 & 155 & 10,078 & $-14,304$ & 1 & 1,116 \\
\hline July & 2,908 & $-7,138$ & 0 & 88 & 7,545 & $-8,490$ & 0 & 691 \\
\hline August & 1,609 & $-4,560$ & 0 & 92 & 9,706 & $-7,232$ & -1 & 709 \\
\hline September & 1,810 & $-5,440$ & 0 & 158 & 7,907 & $-14,448$ & -1 & 1,073 \\
\hline October & 2,271 & $-1,260$ & 0 & 139 & 9,818 & $-8,487$ & 2 & 860 \\
\hline November & 1,900 & $-4,900$ & 0 & 161 & 5,750 & $-4,251$ & 0 & 816 \\
\hline December & 2,200 & $-6,217$ & 0 & 168 & 6,669 & $-5,217$ & -1 & 677 \\
\hline January ('01) & 2,240 & $-2,810$ & 0 & 207 & 8,711 & $-5,075$ & 1 & 685 \\
\hline 12-month & & & 0 & 168 & & & 0 & 1,103 \\
\hline
\end{tabular}


Table 4-2. (continued) Maximum, Average, and Standard Deviation of Lake Benton II Step Changes

\begin{tabular}{lclcr}
\hline Month & \multicolumn{4}{c}{ Hourly power (kW) } \\
\hline & $\begin{array}{c}\text { Max. } \\
\text { Increase }\end{array}$ & $\begin{array}{c}\text { Mecrease } \\
\text { February }\end{array}$ & Mean & Stdev. \\
March & 52,024 & $-50,395$ & -177 & 11,245 \\
April & 49,567 & $-39,605$ & -149 & 11,007 \\
May & 44,420 & $-51,653$ & -98 & 11,478 \\
June & 61,949 & $-38,378$ & -69 & 10,080 \\
July & 42,110 & $-45,712$ & -131 & 7,573 \\
August & 47,425 & $-42,012$ & 29 & 9,757 \\
September & 65,410 & $-35,646$ & 27 & 10,097 \\
October & 50,448 & $-36,868$ & 24 & 9,231 \\
November & 61,159 & $-34,480$ & -141 & 10,069 \\
December & 53,367 & $-48,510$ & -91 & 10,956 \\
January ('01) & 61,033 & $-43,496$ & 21 & 10,801 \\
12-month & & & -56 & 10,220 \\
\hline & & & &
\end{tabular}

Because wind speed can change substantially during an hour, hourly power changes can be very large. The maximum 1-hour increase during the 12-month period (from February 2000 to January 2001) is 65.4 MW (63\% of total capacity), and the maximum 1-hour decrease is 51.7 MW (50\% of total capacity). In terms of $\mathrm{kW}$ per minute, this is equivalent to a positive $1,090 \mathrm{~kW} / \mathrm{min}$ and a negative $860 \mathrm{~kW} / \mathrm{min}$, respectively; both are much less than the maximum 1-minute changes. However, those are relatively infrequent events, as will be shown later in the distribution plot.

Table 4-3 lists average and standard deviation values of positive and negative monthly step changes. It also shows that positive and negative step changes have about the same average absolute values, which implies that step changes are evenly distributed around their means. The averages of all step change values are nearly zero for all cases. The standard deviation for 1-second step changes is $168 \mathrm{~kW}$, less than $0.2 \%$ of total capacity. For 1 -minute step changes, the standard deviation is $1,103 \mathrm{~kW}$, or $1 \%$ of total capacity. For hourly step changes, it is $10,220 \mathrm{~kW}$, or about $9.9 \%$ of total capacity. These relatively small standard-deviation values also suggest that step change distributions are tightly centered around their means. Plots of step change distributions for different time step sizes ( Figure 4-3) confirm the even distribution. 
Table 4-3. Average and Standard Deviations of Positive and Negative Step Changes

\begin{tabular}{lcccccccc}
\hline \multicolumn{1}{c}{ Month } & \multicolumn{3}{c}{ 1-second power (kW) } & \multicolumn{3}{c}{ 1-minute average (kW) } \\
\hline & $(+)$ Avg & $(+)$ Stdev. & $(-)$ Avg & $(-)$ Stdev & (+) Avg & (+) Stdev. & $(-)$ Avg & $(-)$ Stdev \\
February & 107 & 151 & -103 & 186 & 499 & 683 & -502 & 1,193 \\
March & 86 & 125 & -82 & 233 & 507 & 897 & -500 & 2,147 \\
April & 96 & 134 & -92 & 242 & 606 & 1,335 & -604 & 1,954 \\
May & 92 & 146 & -88 & 207 & 552 & 955 & -553 & 1,412 \\
June & 83 & 122 & -78 & 151 & 569 & 781 & -575 & 1,117 \\
July & 54 & 74 & -49 & 84 & 363 & 553 & -368 & 634 \\
August & 60 & 74 & -55 & 77 & 426 & 531 & -437 & 601 \\
September & 97 & 131 & -92 & 147 & 560 & 766 & -559 & 1,051 \\
October & 84 & 115 & -78 & 126 & 491 & 674 & -490 & 783 \\
November & 99 & 135 & -95 & 139 & 489 & 599 & -489 & 752 \\
December & 106 & 144 & -102 & 146 & 452 & 511 & -458 & 577 \\
January ('01) & 126 & 180 & -121 & 184 & 422 & 538 & -420 & 624 \\
12-month & 91 & 133 & -86 & 170 & 494 & 783 & -497 & 1,196 \\
\hline & & & & & & & & \\
\hline
\end{tabular}


Table 4-3. (continued) Average and Standard Deviations of Positive and Negative Step Changes

\begin{tabular}{lrrrr}
\hline \multicolumn{1}{c}{ Month } & \multicolumn{5}{c}{ Hourly average (kW) } \\
\hline & $(+)$ Avg & $(+)$ Stdev. & $(-)$ Avg & $(-)$ Stdev \\
February & 7,574 & 7,530 & $-8,235$ & 8,587 \\
March & 7,169 & 9,213 & $-6,580$ & 8,131 \\
April & 7,818 & 8,805 & $-7,203$ & 8,569 \\
May & 6,724 & 7,784 & $-6,373$ & 7,490 \\
June & 6,885 & 7,693 & $-6,504$ & 7,034 \\
July & 4,439 & 5,992 & $-4,759$ & 6,223 \\
August & 6,219 & 7,098 & $-6,693$ & 7,612 \\
September & 7,204 & 8,096 & $-7,352$ & 7,287 \\
October & 6,146 & 7,206 & $-6,131$ & 6,499 \\
November & 7,145 & 8,063 & $-6,833$ & 7,133 \\
December & 7,634 & 9,379 & $-6,849$ & 7,690 \\
January ('01) & 7,069 & 9,056 & $-6,649$ & 7,752 \\
12-month & 6,844 & 8,116 & $-6,649$ & 7,562 \\
\hline
\end{tabular}




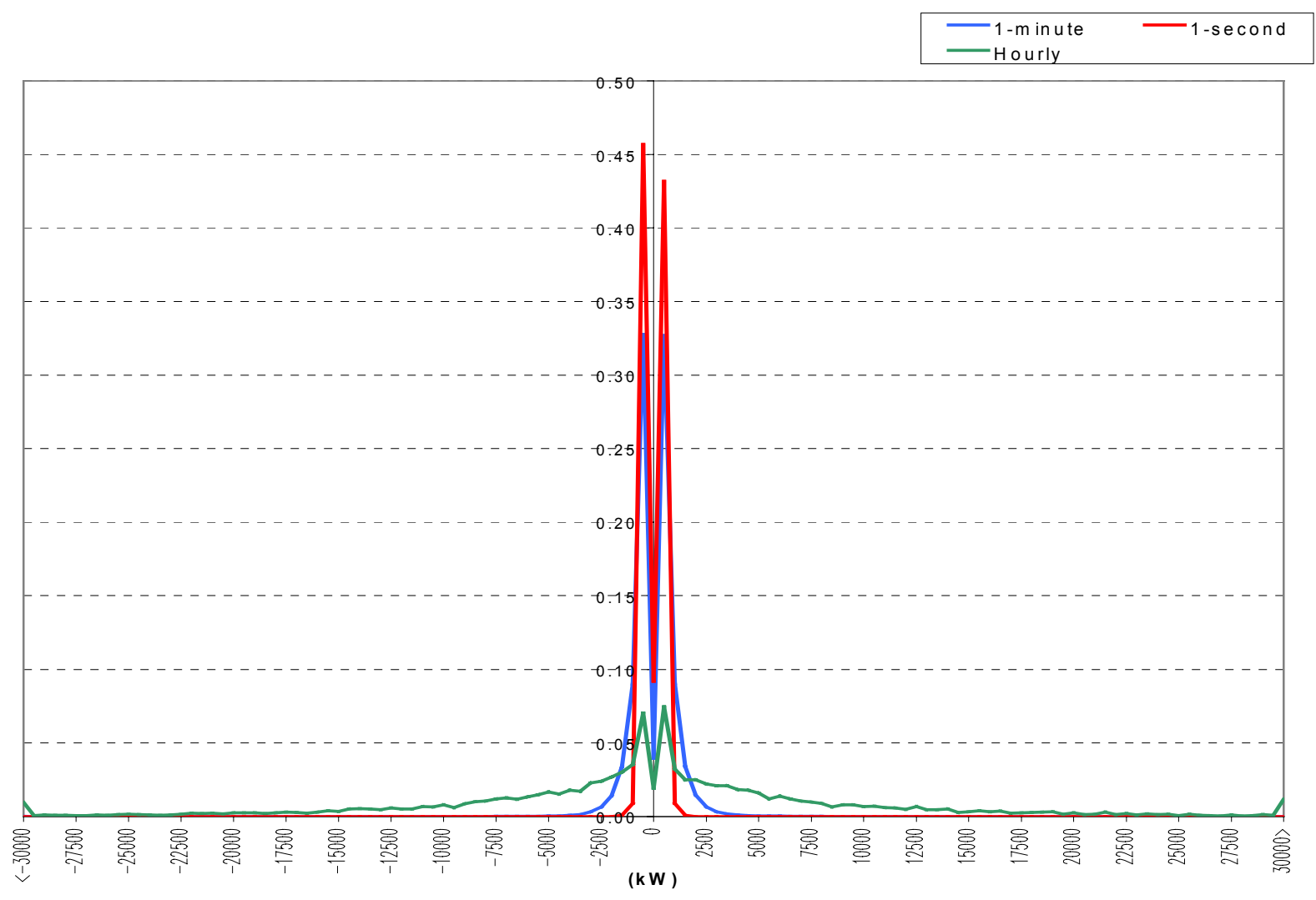

Figure 4-3. Distribution of step changes

These curves do not resemble the familiar bell-shaped normal distribution because of a deep notch at the zero value. The low probability of zero step change values confirms the observation that wind speed and wind power plant output are not static. This low probability is largely the result of zero output values in the data stream (caused by planned and forced outages). Without these zero output values in the data stream, the actual probability of zero step changes would be almost zero. These plots confirm that the short-term power fluctuations are confined to a very narrow range and that the frequencies of positive and negative changes are about the same. Large step changes rarely occur. Most of the step changes have small values.

From the hourly step change distribution curve, we calculated that $78.7 \%$ of the possible step changes are confined within the range of $\pm 10,500 \mathrm{~kW}$ (roughly $\pm 1 \sigma$ ), which is about $10 \%$ of total capacity. Further, $93.6 \%$ of the possible step change values are within $\pm 20,500 \mathrm{~kW}$ (approximately $\pm 2 \sigma$ ), or only about $20 \%$ of total capacity. For 1-minute data, the concentration is more prominent: $87.5 \%$ of the possible step changes are within $\pm 1,000 \mathrm{~kW}( \pm 0.9 \sigma)$ and $94.5 \%$ within $\pm 1,500 \mathrm{~kW}( \pm 1.4 \sigma)$, which is only $1.4 \%$ of the total wind power plant capacity. For 1 -second step change, $98 \%$ of the values are within $\pm 500 \mathrm{~kW}( \pm 3 \sigma)$, or less than $0.5 \%$ of total capacity.

The statistics of step changes for combined output (for the month of January 2001) from Lake Benton II and Storm Lake are listed in Table 4-4. The numbers in parentheses show the quantities as a percentage of total installed capacity of these two wind power plants. 
Table 4-4. Step Changes of Combined Output

\begin{tabular}{|c|c|c|c|}
\hline \multicolumn{4}{|c|}{ 1-hour data } \\
\hline & Lake Benton II & Storm Lake & Combined Output \\
\hline Maximum (+) & $61,033(59 \%)$ & $29,282(26 \%)$ & $63,142(29 \%)$ \\
\hline Maximum (-) & $-43,496(42 \%)$ & $-41,143(36 \%)$ & $-46,290(21 \%)$ \\
\hline Average & 35 & 79 & 111 \\
\hline $\begin{array}{l}\text { Standard } \\
\text { Deviation }\end{array}$ & $10,724(10 \%)$ & $7,609(6.7 \%)$ & $12,800(5.9 \%)$ \\
\hline \multicolumn{4}{|c|}{ 1-minute data } \\
\hline & Lake Benton II & Storm Lake & Combined Output \\
\hline Maximum (+) & $8,711(8 \%)$ & $9,524(8 \%)$ & $5,068(3 \%)$ \\
\hline Maximum (-) & $-5,075(5 \%)$ & $-4,372(4 \%)$ & $-5,445(3 \%)$ \\
\hline Average & 1 & 1 & 2 \\
\hline $\begin{array}{l}\text { Standard } \\
\text { Deviation }\end{array}$ & $707(1 \%)$ & $559(1 \%)$ & $885(0.4 \%)$ \\
\hline
\end{tabular}

1-second data

\begin{tabular}{lccc}
\hline & Lake Benton II & Storm Lake & Combined Output \\
Maximum (+) & $2,240(2 \%)$ & $2,864(3 \%)$ & $2,850(1 \%)$ \\
Maximum (-) & $-2,810(3 \%)$ & $-2,791(3 \%)$ & $-3,073(1 \%)$ \\
Average & 0 & 0 & 0 \\
$\begin{array}{l}\text { Standard } \\
\text { Deviation }\end{array}$ & $207(0.2 \%)$ & $95(0.1 \%)$ & $229(0.1 \%)$ \\
\hline
\end{tabular}

These data reveal that if the output from the Lake Benton II and Storm Lake wind power plants are combined, the average magnitude and standard deviation of power fluctuations may be slightly higher. However, if the step changes are expressed as a percentage of total power, the fluctuations from the combined power output are always smaller than those from either wind power plant. Because these two outputs are not totally independent (the correlation coefficient is not zero), the average value of combined power step changes will not be the sum of two individual averages of power step changes, nor is the combined standard deviation the sum of two individual standard deviations. The maximum values of step 
changes of the combined power can be higher or lower than the maximum values from individual wind power plants. They depend on whether the extreme values from these two sites coincide. Again, this is the result we would expect from two weakly correlated signals.

\section{Ramping Rate}

Step changes show all the single extreme values (instant changes) that the wind power plant can experience; however, those maximum values in either direction occur only infrequently. To investigate sustained power changes, we calculated ramping rates in either direction for various periods. The ramping rates discussed here are slopes of a straight line used to fit the wind power data points. Table 4-5 lists the ramping rates in kilowatts per second calculated with 1-second power data in three time intervals: 5,10 , and 15 seconds. Table 4-6 lists ramping rates in $\mathrm{kW}$ per minute, calculated with 1-minute average power in two time intervals: 5-minute and 10-minute. Sudden power drops and rapid power increases caused by forced or maintenance outages and manual startups are excluded from the maximum $(+)$ and minimum (-) ramping rates in Tables 4-5 and 4-6. However, when calculating average and standard deviation of ramping rates, unaltered data streams are used for the sake of computation expediency (to avoid the problems of data discontinuity).

Ramping rates are higher when computed at shorter time intervals. In Table 4-1, short-term maximum up and down ramping rates are lower than single step change values, indicating the changing nature of the wind speed. Wind power does not move in either up or down direction very long before it reverses itself. It is common for wind power to display a general up-or-down trend over longer periods, e.g., several hours. Tables 4-5 and 4-6 show that average positive (up) and negative (down) ramping rates have approximately the same magnitude on a monthly basis. On a daily basis, this is not necessarily true. 
Table 4-5. Ramping Rates (kW/s) Based on 1-Second Power Data

\begin{tabular}{|c|c|c|c|c|c|c|}
\hline \multirow[t]{2}{*}{ Month } & \multicolumn{6}{|c|}{ 5-second interval } \\
\hline & $\begin{array}{c}\text { Max. }(+) \\
\text { ramp }\end{array}$ & Average & Std. Dev. & $\begin{array}{c}\text { Max. (-) } \\
\text { ramp }\end{array}$ & Average & Std. Dev. \\
\hline February & 1,075 & 41 & 48 & -568 & -42 & 95 \\
\hline March & 1,055 & 35 & 49 & $-1,248$ & -38 & 145 \\
\hline April & 2,921 & 43 & 57 & $-1,553$ & -44 & 146 \\
\hline May & 1,282 & 36 & 48 & $-4,679$ & -41 & 104 \\
\hline June & 3,009 & 42 & 52 & $-3,982$ & -42 & 80 \\
\hline July & 3,299 & 27 & 40 & $-2,901$ & -30 & 47 \\
\hline August & 649 & 35 & 43 & $-1,985$ & -35 & 46 \\
\hline September & 4,166 & 47 & 56 & $-1,971$ & -48 & 72 \\
\hline October & 1,385 & 39 & 53 & $-3,509$ & -43 & 63 \\
\hline November & 960 & 39 & 47 & -805 & -43 & 57 \\
\hline December & 1,758 & 36 & 45 & -821 & -43 & 51 \\
\hline January (01) & 968 & 36 & 44 & $-3,777$ & -43 & 56 \\
\hline 12-month & & 37 & 49 & & -41 & 88 \\
\hline
\end{tabular}


Table 4-5. (continued) Ramping Rates (kW/s) Based on 1-Second Power Data

\begin{tabular}{|c|c|c|c|c|c|c|}
\hline \multirow[t]{2}{*}{ Month } & \multicolumn{6}{|c|}{ 10-second interval } \\
\hline & $\begin{array}{l}\text { Max. }(+) \\
\text { ramp }\end{array}$ & Average & Std. Dev. & $\begin{array}{c}\text { Max. (-) } \\
\text { ramp }\end{array}$ & Average & Std. Dev \\
\hline February & 946 & 31 & 36 & -517 & -31 & 70 \\
\hline March & 855 & 27 & 38 & $-1,070$ & -28 & 109 \\
\hline April & 2,778 & 32 & 46 & $-1,443$ & -32 & 106 \\
\hline May & 1,236 & 27 & 37 & $-1,257$ & -30 & 74 \\
\hline June & 2,626 & 32 & 39 & $-2,157$ & -33 & 60 \\
\hline July & 1,699 & 22 & 31 & $-1,513$ & -23 & 36 \\
\hline August & 525 & 28 & 34 & $-1,020$ & -28 & 37 \\
\hline September & 2,090 & 37 & 44 & $-1,090$ & -37 & 56 \\
\hline October & 1,232 & 31 & 42 & $-2,543$ & -34 & 49 \\
\hline November & 464 & 29 & 35 & -646 & -32 & 43 \\
\hline December & 733 & 26 & 32 & -635 & -31 & 37 \\
\hline January (01) & 575 & 24 & 31 & $-2,086$ & -30 & 40 \\
\hline 12-month & & 28 & 37 & & -31 & 65 \\
\hline
\end{tabular}


Table 4-5. (continued) Ramping Rates (kW/s) Based on 1-Second Power Data

\begin{tabular}{|c|c|c|c|c|c|c|}
\hline & \multicolumn{6}{|c|}{15 -second interval } \\
\hline & $\begin{array}{l}\text { Max. }(+) \\
\text { ramp }\end{array}$ & Average & Std. Dev. & $\begin{array}{l}\text { Max. (-) } \\
\text { ramp }\end{array}$ & Average & Std. Dev \\
\hline February & 900 & 26 & 31 & -376 & -26 & 58 \\
\hline March & 817 & 23 & 32 & -781 & -23 & 92 \\
\hline April & 2,657 & 27 & 42 & -958 & -27 & 88 \\
\hline May & 1,218 & 23 & 32 & -859 & -25 & 61 \\
\hline June & 2,061 & 27 & 33 & $-1,585$ & -27 & 51 \\
\hline July & 884 & 19 & 26 & $-1,031$ & -19 & 30 \\
\hline August & 483 & 24 & 29 & -709 & -24 & 31 \\
\hline September & 1,376 & 31 & 37 & -777 & -31 & 47 \\
\hline October & 1,068 & 26 & 36 & $-1,975$ & -28 & 41 \\
\hline November & 378 & 24 & 30 & -415 & -27 & 36 \\
\hline December & 585 & 21 & 27 & -579 & -26 & 30 \\
\hline January (01) & 479 & 19 & 25 & $-1,439$ & -24 & 33 \\
\hline 12-month & & 24 & 32 & & -26 & 54 \\
\hline
\end{tabular}

For 5-second intervals, the maximum ramping-up rate is about $4,166 \mathrm{~kW} / \mathrm{s}$, or $4.0 \%$ of total capacity per second. The maximum ramping-down rate is $-4,679 \mathrm{~kW}$ per second, or $4.5 \%$ of total capacity. The average values for both ramping-up and ramping-down rates are much smaller, with a magnitude of $37 \mathrm{~kW} / \mathrm{s}$ and $41 \mathrm{~kW} / \mathrm{s}$, respectively. They are less than $0.04 \%$ of total capacity per second. 
Table 4-6. Ramping Rates (kW/min) Based on 1-minute Average Power Data

\begin{tabular}{|c|c|c|c|c|c|c|}
\hline \multirow[t]{2}{*}{ Month } & \multicolumn{6}{|c|}{ 5-minute interval } \\
\hline & $\begin{array}{c}\text { Max. }(+) \\
\operatorname{ramp}\end{array}$ & Average & Std. Dev. & Max. (-) ramp & Average & Std. Dev. \\
\hline February & 4,209 & 367 & 542 & $-4,536$ & -368 & 766 \\
\hline March & 4,162 & 358 & 675 & $-3,881$ & -356 & 1,196 \\
\hline April & 7,375 & 424 & 842 & $-9,569$ & -425 & 1,170 \\
\hline May & 6,024 & 356 & 648 & $-5,115$ & -381 & 860 \\
\hline June & 8,038 & 385 & 555 & $-7,379$ & -387 & 701 \\
\hline July & 8,797 & 237 & 369 & $-6,097$ & -244 & 409 \\
\hline August & 6,421 & 285 & 372 & $-5,992$ & -293 & 416 \\
\hline September & 4,220 & 368 & 498 & $-4,581$ & -364 & 629 \\
\hline October & 8,378 & 297 & 428 & $-11,894$ & -319 & 479 \\
\hline November & 4,123 & 305 & 417 & $-4,575$ & -337 & 478 \\
\hline December & 5,941 & 271 & 376 & $-4,690$ & -326 & 401 \\
\hline January (01) & 5,421 & 266 & 403 & $-4,540$ & -320 & 437 \\
\hline 12-month & & 320 & 530 & & -343 & 723 \\
\hline
\end{tabular}


Table 4-6. Ramping Rates (kW/min) Based on 1-minute Average Power Data (continued)

\begin{tabular}{|c|c|c|c|c|c|c|}
\hline \multirow[t]{2}{*}{ Month } & \multicolumn{6}{|c|}{ 10-minute interval } \\
\hline & $\begin{array}{l}\text { Max. }(+) \\
\operatorname{ramp}\end{array}$ & Average & Std. Dev. & Max. (-) ramp & Average & Std. Dev. \\
\hline February & 2,896 & 312 & 470 & $-3,651$ & -315 & 555 \\
\hline March & 3,780 & 299 & 570 & $-2,785$ & -295 & 809 \\
\hline April & 4,823 & 337 & 610 & $-6,492$ & -335 & 763 \\
\hline May & 4,985 & 287 & 500 & $-6,617$ & -295 & 590 \\
\hline June & 5,429 & 312 & 450 & $-5,627$ & -310 & 515 \\
\hline July & 5,238 & 191 & 304 & $-5,562$ & -194 & 322 \\
\hline August & 4,577 & 238 & 318 & $-4,970$ & -244 & 344 \\
\hline September & 3,257 & 292 & 403 & $-3,911$ & -286 & 447 \\
\hline October & 6,918 & 240 & 343 & $-6,145$ & -255 & 356 \\
\hline November & 3,531 & 255 & 345 & $-2,789$ & -275 & 366 \\
\hline December & 4,933 & 230 & 328 & $-3,848$ & -270 & 330 \\
\hline January (01) & 4,625 & 233 & 346 & $-3,864$ & -271 & 342 \\
\hline 12-month & & 264 & 426 & & -278 & 509 \\
\hline
\end{tabular}

Ramping rates calculated with 1-minute average power data show a similar pattern-longer time intervals always result in lower ramping-up and ramping-down rates. Within a 5-minute interval, the wind power plant can ramp up at a rate of $8.8 \mathrm{MW} /$ minute $(8.5 \%$ of total capacity per minute). The maximum ramping-down rate for a 5 -minute interval is $-12 \mathrm{MW} / \mathrm{min}$ ( $11.5 \%$ of total capacity per minute). For a 10-minute interval, the maximum ramping-up and ramping-down rates are about half of that for a 5-minute interval. Again, in all cases, their average values are much smaller-less than $0.4 \%$ of total wind power plant capacity per minute. The small standard deviation values of ramping rates also indicate that short-term ramping rates are small and confined within a narrow range.

The distributions of ramping rates are plotted in Figure 4-4 for 5-second, 10-second, and 15-second intervals and Figure 4-5 for 5-minute and 10-minute intervals. The shapes of the curves are almost identical to those of step changes. From the distribution curves, we can calculate that for 5 -second intervals, $90.3 \%$ of the apparent ramping rates are within $\pm 100 \mathrm{~kW} / \mathrm{s}$. For 10 -second intervals, $94.9 \%$ of apparent ramping rates are within $\pm 100 \mathrm{~kW} / \mathrm{s}$, and for 15 -second intervals, $96.8 \%$ are within $\pm 100 \mathrm{~kW} / \mathrm{s}$. For longer time, the ranges are even narrower. For 5-minute intervals, $90 \%$ of apparent ramping rates are 
within $\pm 780 \mathrm{~kW} / \mathrm{min}$ (or $13 \mathrm{~kW} / \mathrm{s}$ ). For 10 -minute intervals, $90 \%$ of apparent ramping rates are within $\pm 640 \mathrm{~kW} / \mathrm{min}$ (or $11 \mathrm{~kW} / \mathrm{s}$ ).

These results suggest that if another power plant were to be dedicated to regulate ${ }^{2}$ the output of Lake Benton II, the duty requirement for the dedicated power plant will be $\pm 220 \mathrm{~kW} / \mathrm{s}$ (or about $0.2 \%$ of the total installed capacity per second). This range would cover $99 \%$ of all apparent ramping rates for Lake Benton II.

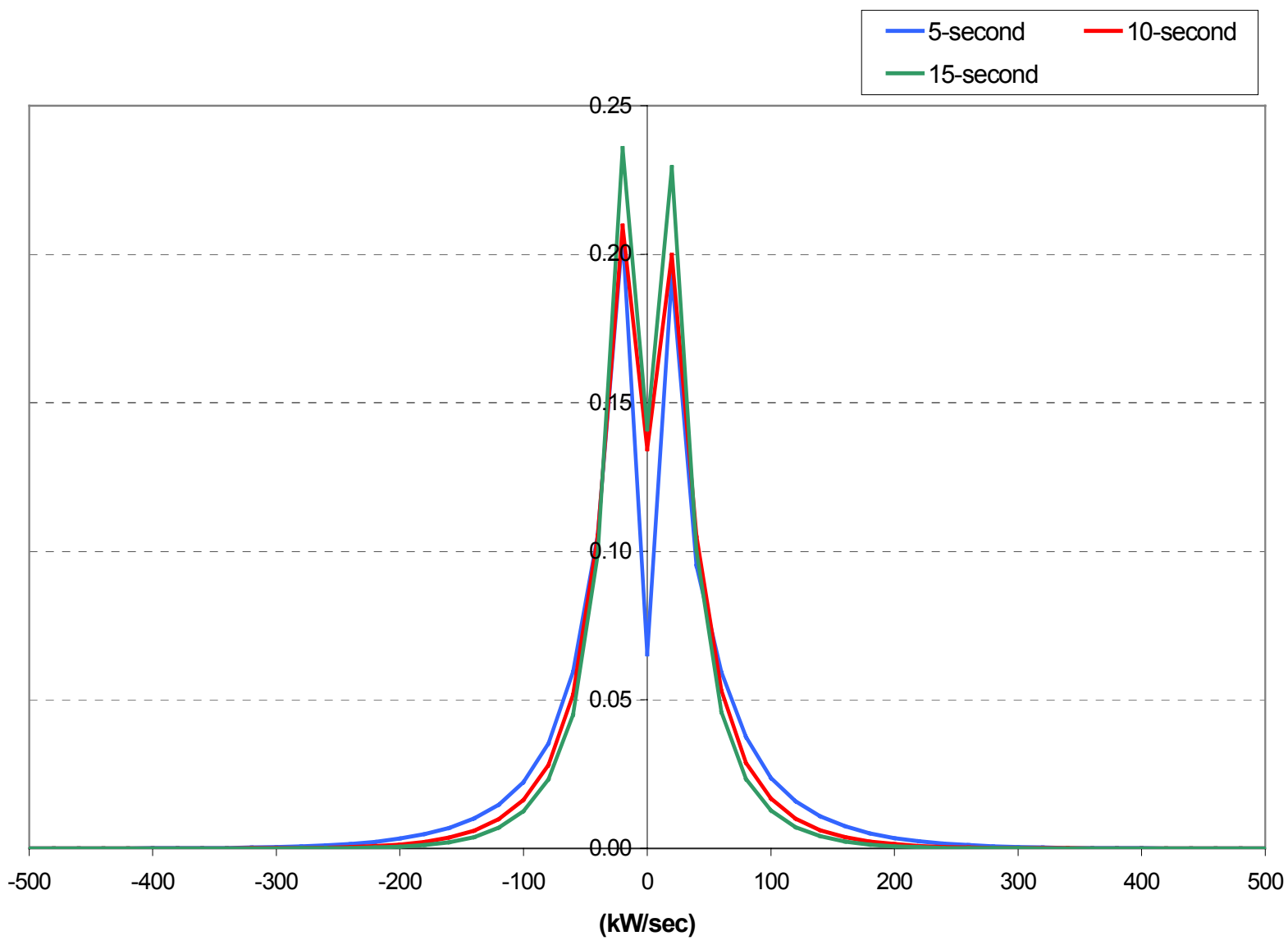

Figure 4-4. Distribution of ramping rates (1)

3 This is not load following as normally applied to electric power systems. In order to do load following, target power levels and generators are controlled to match the changing load level. How fast the target power level can change in any given time interval will determine the duty requirements (ramping rates) of generators that are used to follow it. Here, the rates of change in wind power plant output are used directly as the duty requirements of generators, as if these generators will be running in opposite directions of the wind power plant to cancel those changes. 


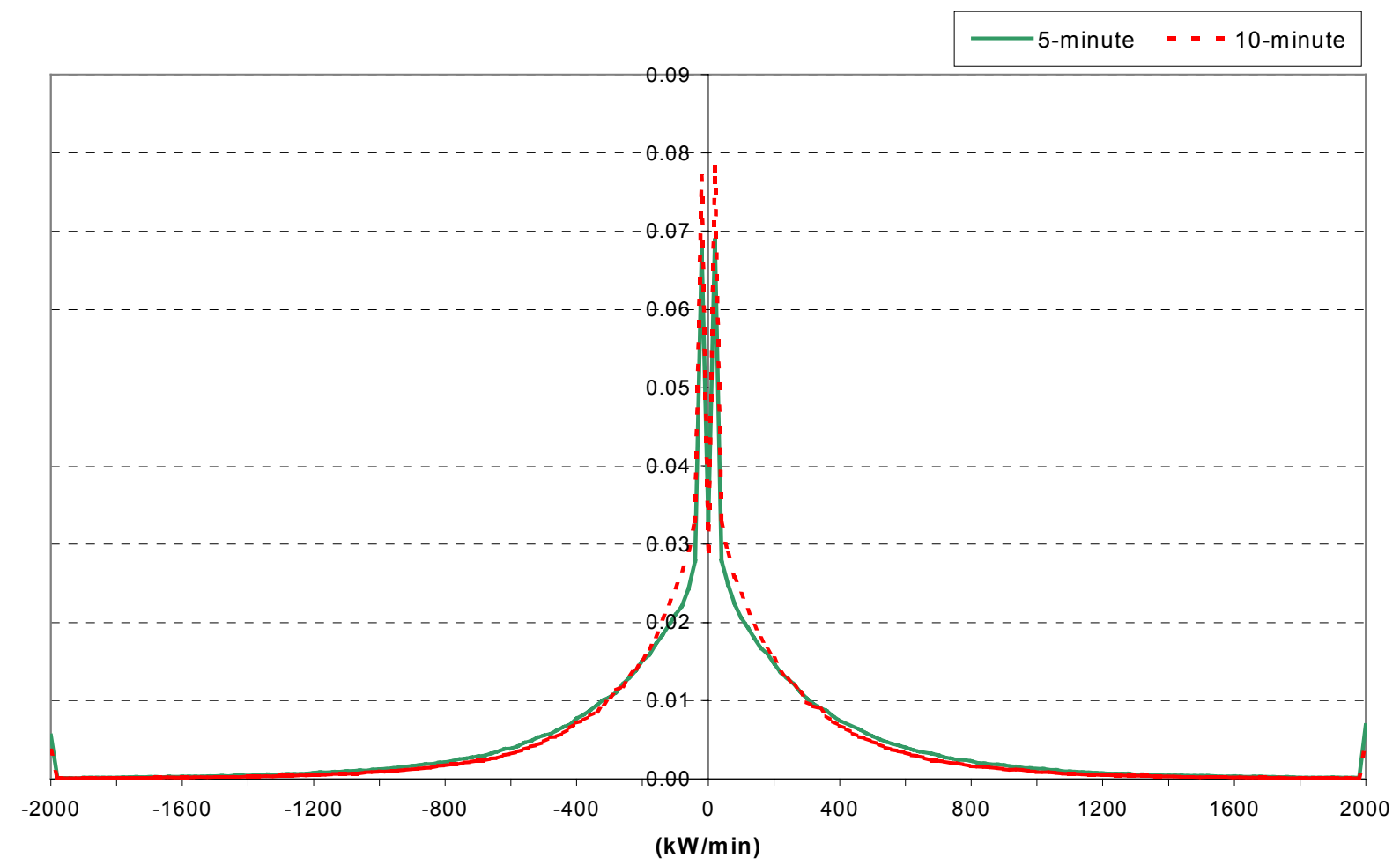

Figure 4-5. Distribution of ramping rates (2)

Average ramping rates and their standard deviations are affected by many forced outages of the wind power plant from February until July, which is reflected in higher standard deviation values during these six months (especially for negative ramping [power levels ramping down] rates). This is because forced and maintenance outages will result in precipitous power drops and, consequently, very large negative ramping rates. Lake Benton II experienced many outages prior to summer of 2000 . The data collected at the grid interconnection points are not sufficient to determine the causes of these outages. However, data have shown significant improvement in the operations of Lake Benton II wind power plant since July 2000. The average and standard deviation values of ramping rates listed in Tables 4-5 and 4-6 include extreme values not caused by wind. For the six-month period from February to July (Table 4-5), the average coefficient of variations of negative ramping rates (the ratio of standard deviation to average) is 2.7, dropping to 1.4 for the next six-month period. In Table 4-6, they are 2.2 and 1.4, respectively. Wind power plants operating normally can be expected to have smaller values.

\section{State Transitions}

Maximum step changes establish the outside boundaries of wind power fluctuations, while ramping rates indicate that wind power does not change very fast; both of these provide strong evidence of wind power persistency. When wind power data are analyzed for the rates of transition from one power level to another, the persistency of wind power from large wind power plants is even more obvious. Table 4-7 shows the rates of transition from one power level to the next in 1-second intervals for Lake Benton II for the 12-month period. The row headings indicate power levels in the first-second time step, and the column headings indicate power levels in the next-second time step. For example, if the current step power level of Lake Benton II is at $40 \%$ of its nameplate power at any particular second (row labeled with $40 \%$ ), $99.34 \%$ of the time its output will stay at the same level (column with $40 \%$ heading) at the next second. The next second, its power may jump to $50 \%$ of the rated value only $0.32 \%$ of the time, and its 
power level may drop to $30 \%$ of the rated value the next-second $0.34 \%$ of the time. This should not come as a surprise, because all 138 wind turbines at the wind power plant are not likely to change their output at the same instant.

Table 4-7. State Transition Rates with 1-Second Power Data

\begin{tabular}{lllllllllll}
\hline & $\mathbf{1 0} \%$ & $\mathbf{2 0} \%$ & $\mathbf{3 0 \%}$ & $\mathbf{4 0 \%}$ & $\mathbf{5 0 \%}$ & $\mathbf{6 0 \%}$ & $\mathbf{7 0 \%}$ & $\mathbf{8 0 \%}$ & $\mathbf{9 0 \%}$ & $\mathbf{1 0 0 \%}$ \\
\hline $\mathbf{1 0 \%}$ & 0.9993 & 0.0007 & 0 & 0 & 0 & 0 & 0 & 0 & 0 & 0 \\
$\mathbf{2 0 \%}$ & 0.0016 & 0.9968 & 0.0016 & 0 & 0 & 0 & 0 & 0 & 0 & 0 \\
$\mathbf{3 0 \%}$ & 0 & 0.0020 & 0.9955 & 0.0025 & 0 & 0 & 0 & 0 & 0 & 0 \\
$\mathbf{4 0 \%}$ & 0 & 0 & 0.0029 & 0.9940 & 0.0031 & 0 & 0 & 0 & 0 & 0 \\
$\mathbf{5 0 \%}$ & 0 & 0 & 0 & 0.0038 & 0.9924 & 0.0039 & 0 & 0 & 0 & 0 \\
$\mathbf{6 0 \%}$ & 0 & 0 & 0 & 0 & 0.0046 & 0.9892 & 0.0062 & 0 & 0 & 0 \\
$\mathbf{7 0 \%}$ & 0 & 0 & 0 & 0 & 0 & 0.0068 & 0.9852 & 0.0080 & 0 & 0 \\
$\mathbf{8 0 \%}$ & 0 & 0 & 0 & 0 & 0 & 0 & 0.0077 & 0.9813 & 0.0111 & 0 \\
$\mathbf{9 0 \%}$ & 0 & 0 & 0 & 0 & 0 & 0 & 0 & 0.0107 & 0.9764 & 0.0128 \\
$\mathbf{1 0 0 \%}$ & 0 & 0 & 0 & 0 & 0 & 0 & 0 & 0 & 0.0195 & 0.9805 \\
\hline
\end{tabular}

As seen in Table 4-8, state transition rates computed with 1-minute average power data show a different pattern. Non-zero values are no longer clustered diagonally, indicating that given more time, much larger power level changes will occur. It should be noted that many of the outlying values in Table 4-8 are the result of forced or planned outages of the wind power plant, not of dramatic wind speed changes. For example, from Table 4-2 (where large step changes caused by outages were excluded) the maximum 1minute power drops at Lake Benton II from February 2000 to January 2001 was 14.4 MW, or only 14\% of total capacity. A power level change of more than $20 \%$ of the installed capacity in 1 minute is clearly not induced by wind speed change. 
Table 4-8. State Transition Rates with 1-Minute Average Power Data

\begin{tabular}{lllllllllll}
\hline & $\mathbf{1 0} \%$ & $\mathbf{2 0} \%$ & $\mathbf{3 0 \%}$ & $\mathbf{4 0 \%}$ & $\mathbf{5 0 \%}$ & $\mathbf{6 0 \%}$ & $\mathbf{7 0 \%}$ & $\mathbf{8 0 \%}$ & $\mathbf{9 0 \%}$ & $\mathbf{1 0 0 \%}$ \\
\hline $\mathbf{1 0 \%}$ & 0.9923 & 0.0077 & 0 & 0 & 0 & 0 & 0 & 0 & 0 & 0 \\
$\mathbf{2 0 \%}$ & 0.0168 & 0.9632 & 0.0198 & 0.0001 & 0 & 0 & 0 & 0 & 0 & 0 \\
$\mathbf{3 0 \%}$ & 0.0003 & 0.0239 & 0.9481 & 0.0275 & 0.0001 & 0 & 0 & 0 & 0 & 0 \\
$\mathbf{4 0 \%}$ & 0.0002 & 0.0001 & 0.0315 & 0.9358 & 0.0322 & 0.0001 & 0 & 0 & 0 & 0 \\
$\mathbf{5 0 \%}$ & 0.0002 & 0.0001 & 0.0001 & 0.0380 & 0.9267 & 0.0347 & 0.0002 & 0 & 0 & 0 \\
$\mathbf{6 0 \%}$ & 0.0002 & 0.0001 & 0.0002 & 0.0002 & 0.0414 & 0.9157 & 0.0422 & 0 & 0 & 0 \\
$\mathbf{7 0 \%}$ & 0.0001 & 0.0002 & 0.0001 & 0.0001 & 0.0003 & 0.0426 & 0.9176 & 0.0389 & 0.0001 & 0 \\
$\mathbf{8 0 \%}$ & 0.0002 & 0.0001 & 0 & 0.0001 & 0.0001 & 0.0002 & 0.0361 & 0.9251 & 0.0382 & 0 \\
$\mathbf{9 0 \%}$ & 0.0002 & 0 & 0.0001 & 0 & 0 & 0 & 0.0002 & 0.0361 & 0.9416 & 0.0218 \\
$\mathbf{1 0 0 \%}$ & 0 & 0.0001 & 0 & 0 & 0 & 0 & 0.0001 & 0.0004 & 0.0324 & 0.9667 \\
\hline
\end{tabular}

\subsection{Spatial Diversity}

The 138 turbines at Lake Benton II are arranged along a northwest to southeast diagonal line about $17 \mathrm{~km}$ (10.6 miles) long. The operation of turbines is not synchronized, and their outputs do not rise and fall at the same time. When a wind gust sweeps through the site, it reaches some turbines sooner than others. If we monitored the output of every turbine, we should detect an output with a wave-like pattern. Even with data from only four interconnection points, this effect is still detectable.

An example of this effect is given in Figure 4-6, which shows output profiles of the four gridinterconnection points and their sums for a summer day in 2000. They are plotted with 1-minute average power data. The graph shows that, shortly after 21:21, a gust passed through the site, resulting in a power surge of $42 \mathrm{MW}$ within about 13.5 minutes (a ramp rate of $3.1 \mathrm{MW} / \mathrm{min}$ or $52 \mathrm{~kW} / \mathrm{s}$ ). It is also clear from the graph that not all four grid-interconnection points rise to their peak power at the same time. Figure 4-7 shows the details of the gust and power surge in a 20-minute window (from 21:22 to 21:41) plotted with 1 -second power data from these four interconnection points and their sum. 


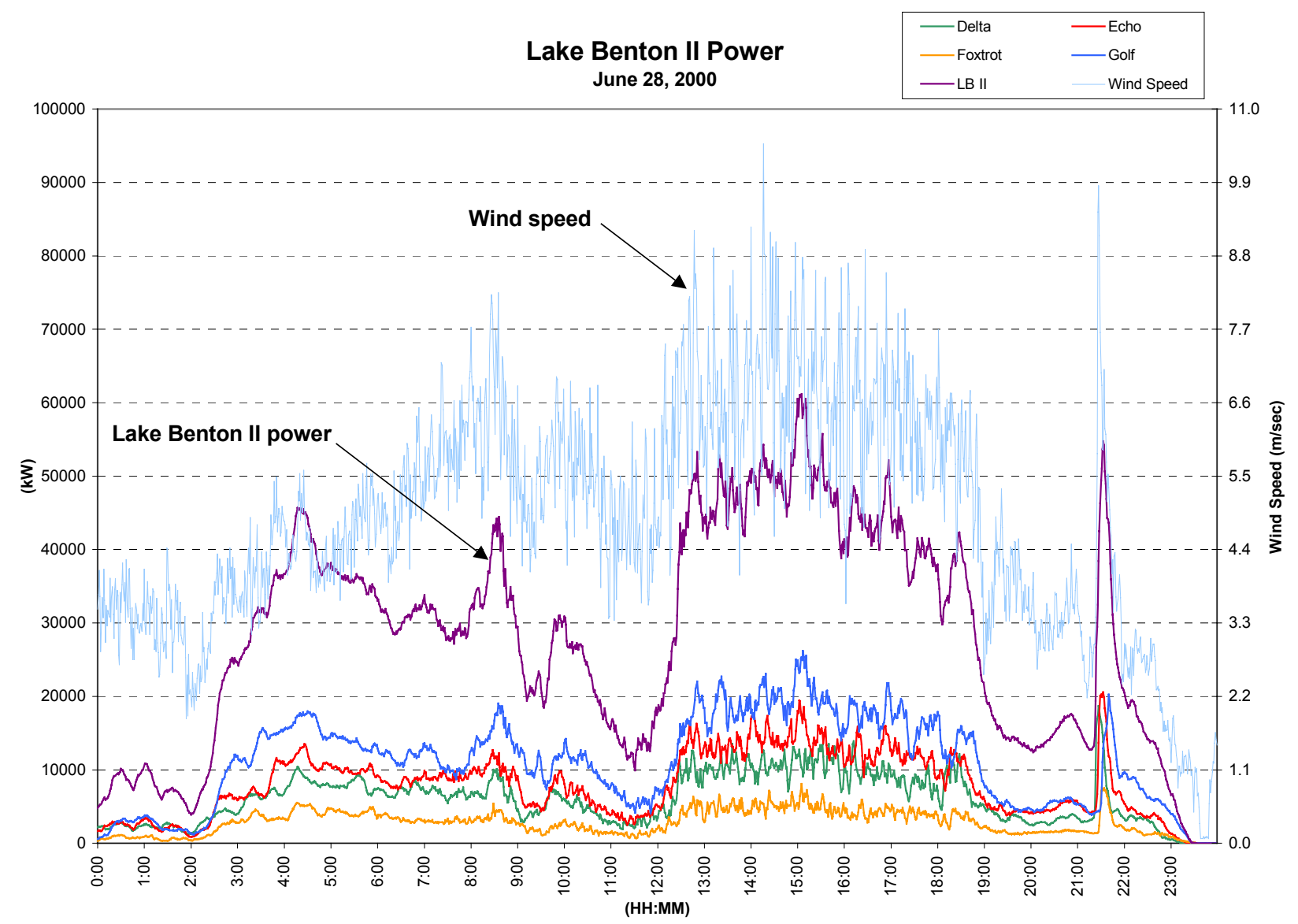

Figure 4-6. Sample daily power output profile

Wind speed data in Figures 4-6 and 4-7 are from an anemometer located at the Echo interconnection point, which is near the middle of the wind power plant. It appears that the direction of the gust is northwest to southeast. The effect of wind turbine separation is clearly seen. Power at the Delta interconnection point rises first, followed by Echo, Foxtrot, and then Golf. The entire plant reaches a peak output of 55.74 MW at 21:33:33, although output power from the Golf interconnection point does not reach its peak until about 7 minutes later at 21:40:29. The peak gust recorded at Echo is about $11 \mathrm{~m} / \mathrm{sec}$ during this period. Golf peak gust occurs about 16 minutes later than the Delta's first peak. This sequential timing corresponds well with the straight-line distance of $10.8 \mathrm{~km}$ between the Delta and Golf interconnection points. The noncoincidental peak during this 20 -minute period (the sum of the four individual peaks in the period) is $69.25 \mathrm{MW}$, if the same gust would have hit all turbines at the same instant. However, the turbines are scattered, and it takes time for the gust to sweep through them. When power from the last group of turbines (Golf interconnection point) begins to rise, power from the first group of turbines (Delta interconnection point) has already begun to drop. As a result, the coincidental peak during this 20 -minute period is only $55.74 \mathrm{MW}$. The coincident factor for this 20 -minute period is 0.805 . 


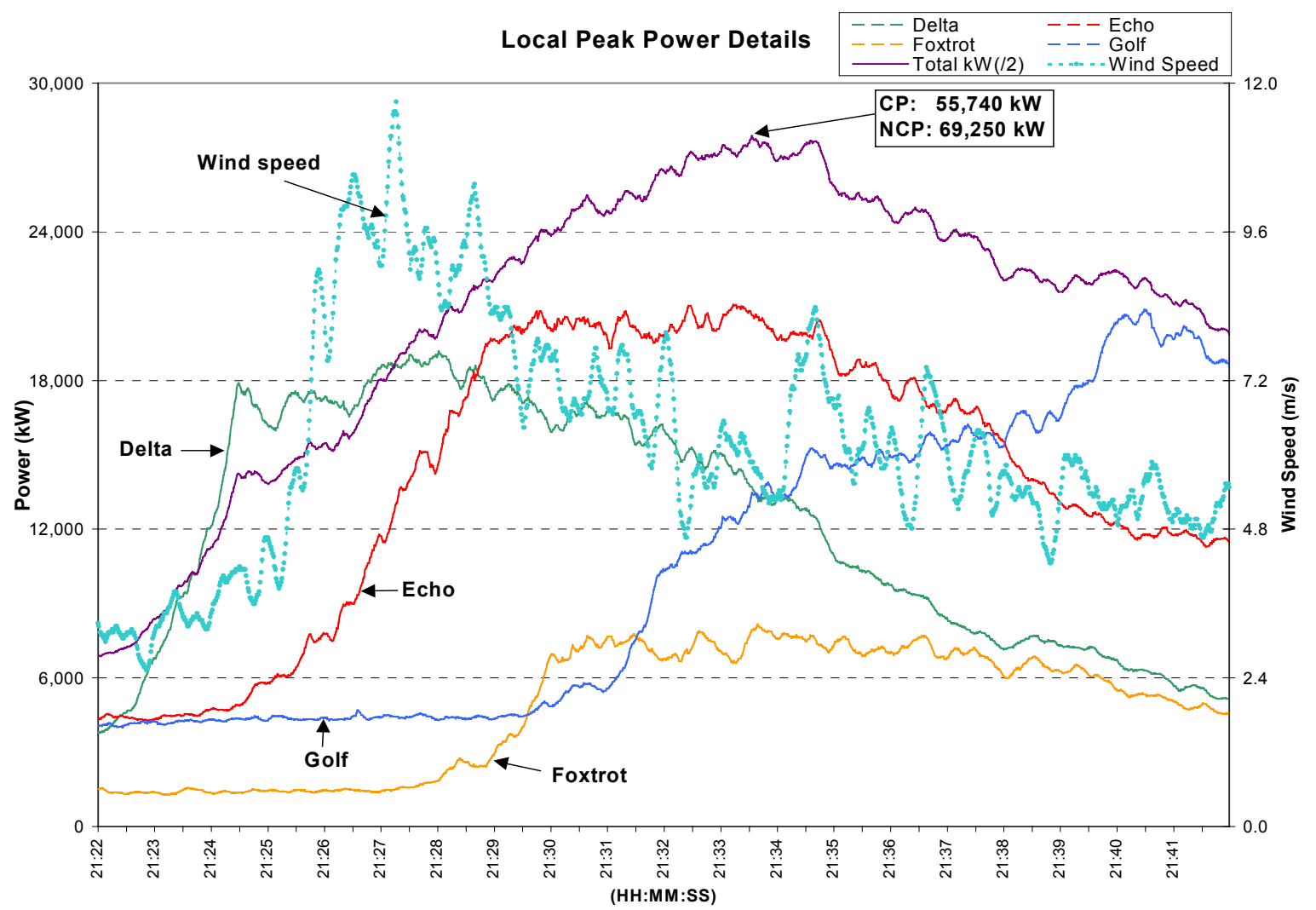

Figure 4-7. Detailed local peak with 1-second data

The coincident factors listed in Table 4-1 are all very high and show only small variations from month to month. The reason for these high coincident factor values in Table 1 is that only one value is taken from each monthly grid-interconnection point to calculate the coincident factors. The example above demonstrates that the coincident factor can have low values. To show their variability, coincident factors are calculated with continuous 1-second data streams from four grid-interconnection points using three window sizes: 60 seconds (60 data points), 10 minutes (600 data points), and 30 minutes (1,800 data points). Table 4-9 shows the monthly averages, standard deviations, and minimum values of coincident factors. The maximum coincident factor values, which equal to 1.0 for all cases, are not included in Table 4-9. 
Table 4-9. Coincident Factors

\begin{tabular}{|c|c|c|c|c|c|c|c|c|c|}
\hline & \multicolumn{3}{|c|}{60 -second } & \multicolumn{3}{|c|}{ 10-minute } & \multicolumn{3}{|c|}{ 30-minute } \\
\hline & Avg & Stdev & Minimum & Avg & Stdev & Minimum & Avg & Stdev & Minimum \\
\hline February & $0.97\rceil$ & 0.049 & 0.356 & 0.944 & $0.08 \mathrm{~s}$ & 0.316 & 0.931 & 0.097 & 0.343 \\
\hline March & $0.96 \varepsilon$ & 0.067 & 0.330 & 0.921 & $0.11 \epsilon$ & 0.315 & 0.902 & 0.131 & 0.309 \\
\hline April & $0.97<$ & 0.052 & 0.315 & 0.932 & $0.09 \varepsilon$ & 0.300 & 0.916 & 0.110 & 0.306 \\
\hline May & 0.97 & 0.055 & 0.352 & 0.930 & $0.10 c$ & 0.326 & 0.913 & 0.113 & 0.325 \\
\hline June & $0.96 i$ & 0.062 & 0.340 & 0.920 & $0.10=$ & 0.310 & 0.906 & 0.109 & 0.329 \\
\hline July & $0.95 \varepsilon$ & 0.070 & 0.323 & 0.902 & $0.11 \varepsilon$ & 0.284 & 0.885 & 0.127 & 0.308 \\
\hline August & $0.96 i$ & 0.067 & 0.326 & 0.913 & 0.114 & $\quad 0.290$ & 0.896 & 0.122 & 0.307 \\
\hline September & 0.971 & 0.058 & 0.352 & 0.932 & $0.09 \varepsilon$ & 0.301 & 0.915 & 0.110 & 0.307 \\
\hline October & $0.96 i$ & 0.062 & 0.318 & 0.923 & 0.105 & 0.337 & 0.906 & 0.114 & 0.328 \\
\hline November & $0.97 \epsilon$ & 0.050 & 0.370 & 0.945 & 0.085 & 0.305 & 0.933 & 0.094 & 0.327 \\
\hline December & $0.97 \varepsilon$ & 0.045 & 0.354 & 0.948 & $0.08<$ & 0.326 & 0.936 & 0.091 & 0.335 \\
\hline January (01) & $0.97 €$ & 0.045 & 0.411 & 0.951 & 0.084 & 0.303 & 0.938 & 0.096 & 0.326 \\
\hline
\end{tabular}

The results show that a wider window size tends to increase the range of coincident factors, as indicated by higher standard deviation values and lower minimum values. For a 30-minute window, the average coincident factors range from 0.89 to 0.94 . The range of standard deviation values is from 0.10 to 0.13 , suggesting that spatial diversity at the Lake Benton II site is probably responsible for an approximately $10 \%$ reduction in peak wind power seen by the utility grid.

Table 4-10 shows the coincident factors calculated with Storm Lake output and Lake Benton II output. Average coincident factors of the combined output power from both Lake Benton II and Storm Lake have a much narrower range compared to the average coincident factors of four grid-interconnection points at Lake Benton. This suggests that if the outputs of these two wind power plants are combined, less peak power reduction will be realized. This result can be attributed to the following:

1. Table 4-9 is calculated with four data streams but Table 4-10 is calculated with only two data streams.

2. The Lake Benton II and Storm Lake power outputs are not totally independent. As discussed in the next section, a closer look at these two power streams will reveal a more complicated co-relationship between Lake Benton II and Storm Lake. 
Table 4-10. Coincident Factors of Lake Benton II and Storm Lake

\begin{tabular}{lcccccccccc}
\hline Month & \multicolumn{3}{c}{60 -second } & \multicolumn{3}{c}{ 10-minute } & \multicolumn{3}{c}{ 30-minute } \\
\hline & Avg & Stdev & Minimum & Avg & Stdev & Minimum & Avg & Stdev & Minimum \\
& January (01) & 0.996 & 0.007 & 0.853 & 0.987 & 0.019 & 0.785 & 0.977 & 0.032 & 0.716 \\
\hline
\end{tabular}

\section{Output Correlation between Grid-Interconnection Points}

The degree of spatial diversity can be examined with the aid of linear correlation coefficients between outputs measured at grid-interconnection points. Wind turbines in close proximity should have output patterns similar to each other, and wind turbines that are spaced farther apart should have more differences in their output patterns. Table 4-11 shows monthly correlation coefficients between grid interconnection points. Calculated linear correlation coefficients show the predicted relationship among power outputs from the four interconnection points. Interconnection points that are adjacent to each other have higher correlation coefficients than those points that are not. In addition, correlation coefficients calculated with longer timeframe data have higher values than those calculated with shorter timeframe data, because the averaging process smoothes out short-duration (high-frequency) variations. The results also suggest that the spacing between individual turbines and the distances between grid-interconnection points are not large enough to cause a more prominent spatial diversity. 
Table 4-11. Output Power Correlation Coefficients Among Interconnection Points

\begin{tabular}{|c|c|c|c|c|c|c|c|c|c|}
\hline & \multicolumn{3}{|c|}{ 1-hour data } & \multicolumn{3}{|c|}{ 10-minute data } & \multicolumn{3}{|c|}{ 1-minute data } \\
\hline & Echo & Foxtrot & Golf & Echo & Foxtrot & Golf & Echo & Foxtrot & Golf \\
\hline \multicolumn{10}{|c|}{ February } \\
\hline Delta & 0.991 & 0.980 & 0.974 & 0.986 & 0.970 & 0.963 & 0.983 & 0.965 & 0.959 \\
\hline Echo & & 0.986 & 0.988 & & 0.981 & 0.980 & & 0.978 & 0.977 \\
\hline Foxtrot & & & 0.983 & & & 0.977 & & & 0.973 \\
\hline \multicolumn{10}{|l|}{ March } \\
\hline Delta & 0.983 & 0.910 & 0.964 & 0.978 & 0.894 & 0.946 & 0.973 & 0.885 & 0.942 \\
\hline Echo & & 0.924 & 0.978 & & 0.913 & 0.965 & & 0.905 & 0.961 \\
\hline Foxtrot & & & 0.933 & & & 0.925 & & & 0.917 \\
\hline \multicolumn{10}{|l|}{ April } \\
\hline Delta & 0.985 & 0.948 & 0.918 & 0.977 & 0.932 & 0.901 & 0.971 & 0.921 & 0.893 \\
\hline Echo & & 0.959 & 0.930 & & 0.949 & 0.917 & & 0.942 & 0.912 \\
\hline Foxtrot & & & 0.959 & & & 0.950 & & & 0.942 \\
\hline \multicolumn{10}{|l|}{ May } \\
\hline Delta & 0.916 & 0.782 & 0.796 & 0.921 & 0.769 & 0.787 & 0.919 & 0.702 & 0.796 \\
\hline Echo & & 0.805 & 0.838 & & 0.795 & 0.822 & & 0.751 & 0.828 \\
\hline Foxtrot & & & 0.812 & & & 0.797 & & & 0.728 \\
\hline \multicolumn{10}{|l|}{ June } \\
\hline Delta & 0.974 & 0.941 & 0.895 & 0.963 & 0.918 & 0.875 & 0.956 & 0.908 & 0.868 \\
\hline Echo & & 0.951 & 0.909 & & 0.938 & 0.894 & & 0.930 & 0.888 \\
\hline Foxtrot & & & 0.897 & & & 0.883 & & & 0.875 \\
\hline
\end{tabular}


Table 4-11. (continued) Output Power Correlation Coefficients Among Interconnection Points

\begin{tabular}{|c|c|c|c|c|c|c|c|c|c|}
\hline & \multicolumn{3}{|c|}{ 1-hour data } & \multicolumn{3}{|c|}{ 10-minute data } & \multicolumn{3}{|c|}{ 1-minute data } \\
\hline & Echo & Foxtrot & Golf & Echo & Foxtrot & Golf & Echo & Foxtrot & Golf \\
\hline \multicolumn{10}{|l|}{ July } \\
\hline Delta & 0.976 & 0.964 & 0.978 & 0.969 & 0.952 & 0.966 & 0.964 & 0.944 & 0.960 \\
\hline Echo & & 0.967 & 0.976 & & 0.962 & 0.968 & & 0.957 & 0.964 \\
\hline Foxtrot & & & 0.977 & & & 0.971 & & & 0.965 \\
\hline \multicolumn{10}{|l|}{ August } \\
\hline Delta & 0.985 & 0.961 & 0.946 & 0.975 & 0.944 & 0.926 & 0.970 & 0.936 & 0.920 \\
\hline Echo & & 0.981 & 0.970 & & 0.974 & 0.957 & & 0.969 & 0.952 \\
\hline Foxtrot & & & 0.978 & & & 0.968 & & & 0.963 \\
\hline \multicolumn{10}{|c|}{ September } \\
\hline Delta & 0.988 & 0.963 & 0.964 & 0.982 & 0.950 & 0.950 & 0.977 & 0.942 & 0.944 \\
\hline Echo & & 0.972 & 0.976 & & 0.962 & 0.964 & & 0.956 & 0.959 \\
\hline Foxtrot & & & 0.984 & & & 0.978 & & & 0.973 \\
\hline \multicolumn{10}{|c|}{ October } \\
\hline Delta & 0.889 & 0.876 & 0.886 & 0.884 & 0.867 & 0.874 & 0.881 & 0.862 & 0.871 \\
\hline Echo & & 0.978 & 0.983 & & 0.971 & 0.973 & & 0.967 & 0.970 \\
\hline Foxtrot & & & 0.985 & & & 0.978 & & & 0.974 \\
\hline \multicolumn{10}{|c|}{ November } \\
\hline Delta & 0.987 & 0.884 & 0.869 & 0.983 & 0.877 & 0.860 & 0.980 & 0.874 & 0.857 \\
\hline Echo & & 0.912 & 0.898 & & 0.908 & 0.890 & & 0.905 & 0.887 \\
\hline Foxtrot & & & 0.959 & & & 0.950 & & & 0.947 \\
\hline \multicolumn{10}{|c|}{ December } \\
\hline Delta & 0.987 & 0.977 & 0.976 & 0.983 & 0.969 & 0.966 & 0.981 & 0.966 & 0.964 \\
\hline Echo & & 0.979 & 0.979 & & 0.974 & 0.972 & & 0.971 & 0.970 \\
\hline Foxtrot & & & 0.985 & & & 0.980 & & & 0.978 \\
\hline
\end{tabular}


Table 4-11. (continued) Output Power Correlation Coefficients Among Interconnection Points

\begin{tabular}{|c|c|c|c|c|c|c|c|c|c|}
\hline & \multicolumn{3}{|c|}{ 1-hour data } & \multicolumn{3}{|c|}{ 10-minute data } & \multicolumn{3}{|c|}{ 1-minute data } \\
\hline & Echo & Foxtrot & Golf & Echo & Foxtrot & Golf & Echo & Foxtrot & Golf \\
\hline \multicolumn{10}{|c|}{ January (01) } \\
\hline Delta & 0.989 & 0.984 & 0.983 & 0.986 & 0.978 & 0.976 & 0.984 & 0.976 & 0.974 \\
\hline Echo & & 0.986 & 0.988 & & 0.982 & 0.982 & & 0.980 & 0.980 \\
\hline Foxtrot & & & 0.989 & & & 0.985 & & & 0.983 \\
\hline
\end{tabular}

\section{Correlation between Two Wind Power Plants}

The distance between the Storm Lake and Lake Benton II wind power plants is about $200 \mathrm{~km}$. Correlation coefficients between these two data streams are calculated to gauge the relationship between the power outputs of these two wind power plants. Table 4-12 lists the correlation coefficients between Lake Benton II and Storm Lake power output based on 1-second, 1-minute, and 1-hour average power and the ranges of daily correlation coefficients for the month of January 2001.

Table 4-12. Correlation Coefficient Between Lake Benton II and Storm Lake

\begin{tabular}{lccc}
\hline & 1-second data & 1-minute data & Hourly data \\
\hline January (01) & 0.1928 & 0.1928 & 0.1967 \\
Daily Range & $(-0.781 \sim 0.876)$ & $(-0.781 \sim 0.876)$ & $(-0.817 \sim 0.897)$ \\
\hline
\end{tabular}

Daily correlation coefficients for these two sites during the month vary from 0.897 (strong positive correlation, i.e., they often are synchronized) to -0.817 (strong negative correlation, i.e., they move in opposite directions). The correlation coefficient for the entire month suggests only a weak co-relationship between power outputs from these two sites.

Figure 4-8 is a plot of the profiles of 10-minute average power output for Lake Benton II and Storm Lake for the first 7 days of year 2001 (from January 1 to January 7, 2001). The correlation coefficient during this period is 0.198 . The low correlation coefficient indicates that these two output streams are not related, but the plot shows that these two output streams are not as random as the simple correlation coefficient calculations have suggested. For example, a closer look at the figure reveals that the output pattern from Storm Lake is actually similar to that of Lake Benton II with a time delay. One of the prominent features in the figure is a plateau in the middle, representing a period of high output at Lake Benton II from 9:00 p.m. on January 3 to 3:00 p.m. on January 5. An almost identical plateau (of lower height because of less generating capacity) from Storm Lake shows up about 9 hours later (beginning 6:00 a.m. on January 4). A calculated correlation coefficient of 0.885 for these two plateaus during this 42 -hour period confirms the observation, suggesting that the same weather event that drives the wind regimes of both sites arrives at Storm Lake about 9 hours later. There is also an output power rise at Storm Lake (from 11:40 p.m. on January 1 to 11:30 p.m. on January 2) that corresponds to the first prominent plateau from Lake Benton II 
shown in Figure 4-8 (from 6:40 a.m. on January 1 to 6:30 a.m. on January 2). A calculated correlation coefficient of 0.891 during this 24 -hour period confirms that these patterns match. However, it has a time delay of 17 hours, longer than the 9-hour delay observed from the second plateau in the figure. Obviously, wind speed and direction probably account for the difference in time delay.

Similar behaviors can be observed at many other times (Figure 4-9). The 10-minute average power profiles of Lake Benton II and Storm Lake for another 7-day period (from January 8, 2001 to January 14, 2001 ) illustrates this. Output profiles from these two wind power plants have very similar shape during this period. The power output of Storm Lake has a shape that is very similar to that of Lake Benton II with a time delay of about 12 hours for the first prominent feature ${ }^{3}$ in the figure and no time delay for the second prominent feature. Calculation of correlation coefficients again confirms the observation. During the 4-day period from January 8 to January 11 , the correlation coefficient is only 0.265 , whereas the correlation coefficient of the Lake Benton II plateau and the time-delayed plateau from Storm Lake is 0.762 .

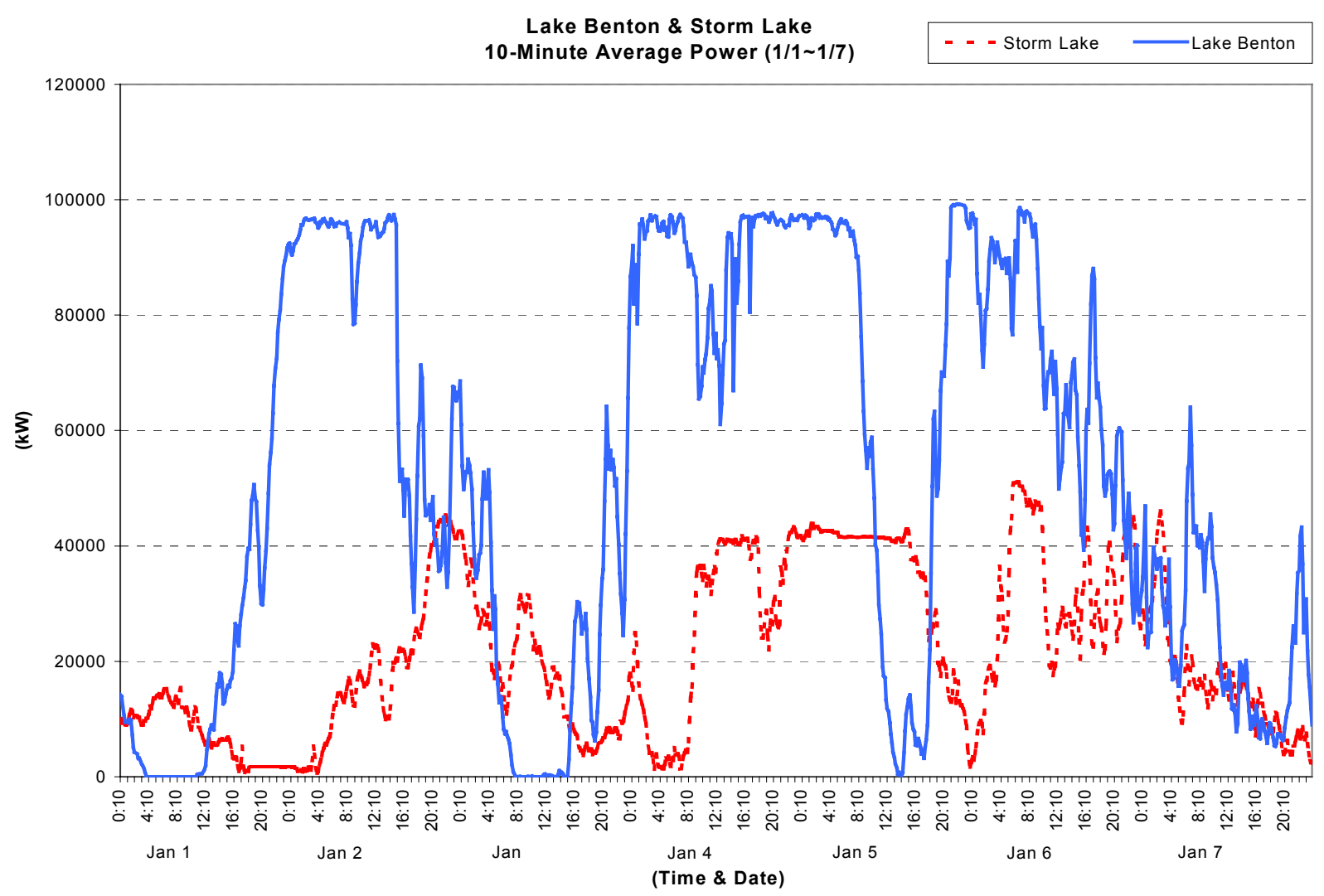

Figure 4-8. Output profiles of Lake Benton II and Storm Lake

3 For Lake Benton II it is a plateau beginning at 9:00 on January 8 and ending at 6:50 on January 11. for Storm Lake it is a plateau beginning at about 21:00on January 8 and ending at 18:50 on January 11. 


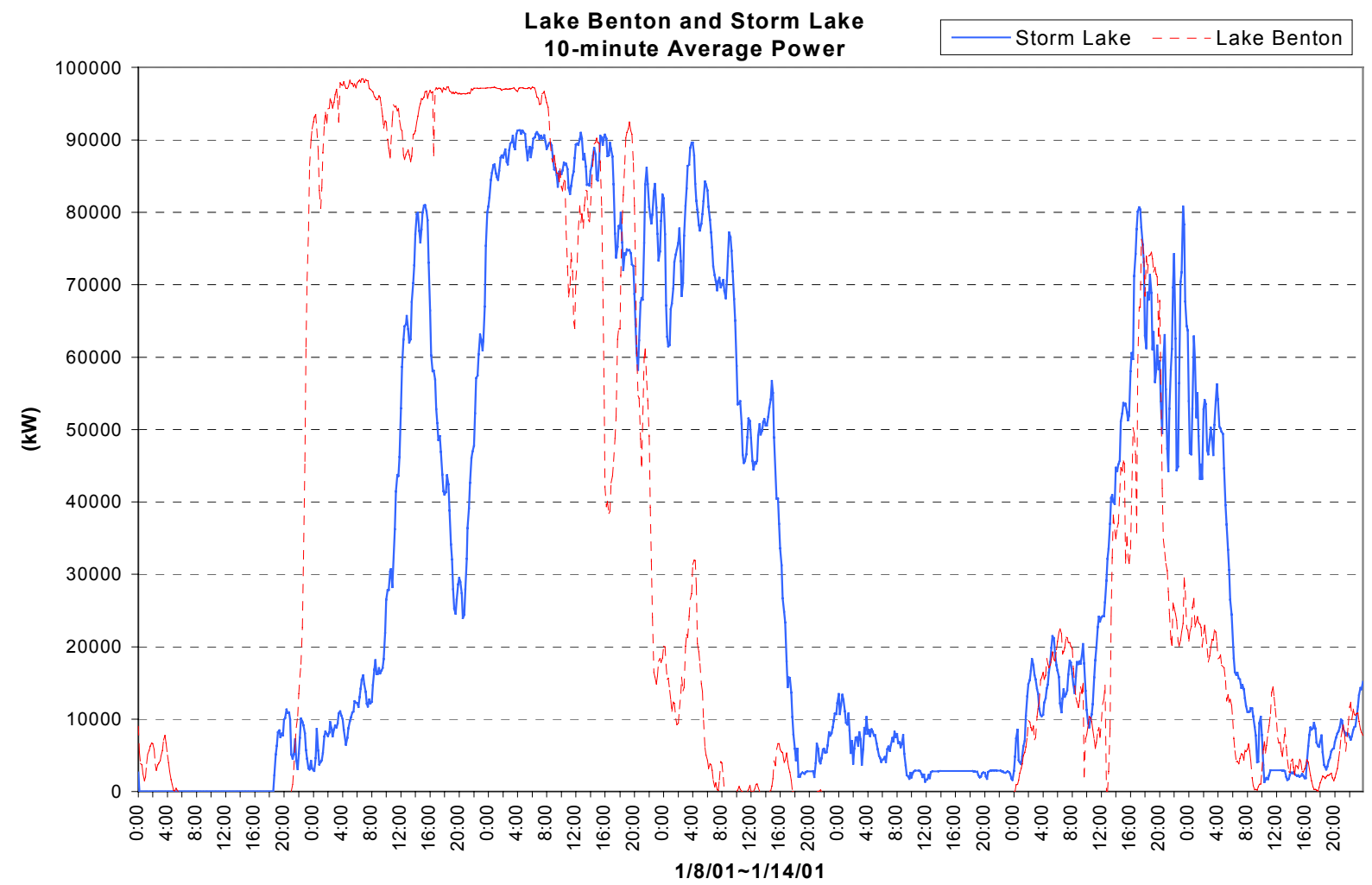

Figure 4-9. Another output profile of Lake Benton II and Storm Lake

\subsection{Wind Power Variability}

Another way to examine the variability of wind speed at different sites is to look at the coefficient of variation (COV), which is the ratio of the standard deviation of wind speed to the mean wind speed. COV of wind speed is known as turbulence intensity of wind. A higher COV indicates more turbulent wind and more fluctuations of wind power. However, a wind power plant with many turbines will attenuate the resulting output power fluctuations. Obviously, this output leveling effect is more prominent with an increasing number of turbines and greater distance between the turbines.

For the wind speed measured at the Echo interconnection point, the calculated COVs range between 0.47 and 0.64. Table 4-13 lists monthly COV values calculated from 1-second, 1-minute, and 10-minute average wind speed data. 
Table 4-13. Coefficient of Variation of Wind Speed at Echo

\begin{tabular}{lccc}
\hline Month & 1-Second Data & 1-Minute Data & 10-Minute Data \\
\hline February & 0.480 & 0.474 & 0.467 \\
March & 0.639 & 0.632 & 0.623 \\
April & 0.596 & 0.589 & 0.579 \\
May & 0.535 & 0.526 & 0.513 \\
June & 0.546 & 0.536 & 0.514 \\
July & 0.677 & 0.661 & 0.643 \\
August & 0.513 & 0.489 & 0.467 \\
September & 0.645 & 0.625 & 0.608 \\
October & 0.518 & 0.510 & 0.496 \\
November & 0.453 & 0.451 & 0.444 \\
December & 0.525 & 0.524 & 0.518 \\
January (01) & 0.728 & 0.727 & 0.724 \\
12-month & 0.623 & 0.616 & 0.607 \\
\hline
\end{tabular}

Available power in the wind is proportional to the cube of wind speed. If the COV is calculated with wind speed cubed and the results are compared to the calculated COV of measured power from the wind plant, a pattern of much reduced variability emerges. Table 4-14 shows the COV values of wind speed cubed and power output at the Echo interconnection point, as well as the entire wind power plant. The reduction in variability is very clear. On average, variability of power output is only about half the variability of wind speed cubed. 
Table 4-14. COV of Wind Speed Cubed, Echo Output, and Lake Benton II Output

\begin{tabular}{lccccccccc}
\hline \multicolumn{1}{c}{ Month } & \multicolumn{3}{c}{ 1-second Data } & \multicolumn{2}{c}{ 1-minute Average } & \multicolumn{3}{c}{ 10-minute Average } \\
\hline & $(m / s e c)^{3}$ & Echo $k W$ & LB2 $k W$ & $(m / s e c)^{3}$ & Echo $k W$ & $L B 2 k W$ & $(m / s e c)^{3}$ & Echo $k W$ & $L B 2 ~ k W$ \\
February & 1.44 & 0.777 & 0.773 & 1.41 & 0.777 & 0.773 & 1.32 & 0.775 & 0.771 \\
March & 1.86 & 0.989 & 0.978 & 1.80 & 0.989 & 0.978 & 1.74 & 0.992 & 0.974 \\
April & 1.87 & 0.823 & 0.815 & 1.81 & 0.823 & 0.815 & 1.76 & 0.818 & 0.812 \\
May & 1.75 & 1.008 & 0.922 & 1.70 & 1.008 & 0.922 & 1.64 & 1.003 & 0.919 \\
June & 1.72 & 0.838 & 0.845 & 1.66 & 0.837 & 0.845 & 1.59 & 0.833 & 0.843 \\
July & 1.78 & 1.228 & 1.172 & 1.66 & 1.228 & 1.172 & 1.56 & 1.223 & 1.171 \\
August & 1.44 & 0.918 & 0.899 & 1.32 & 0.917 & 0.899 & 1.19 & 0.914 & 0.898 \\
September & 1.64 & 0.894 & 0.868 & 1.51 & 0.893 & 0.868 & 1.41 & 0.890 & 0.867 \\
October & 1.29 & 0.936 & 0.911 & 1.26 & 0.936 & 0.911 & 1.18 & 0.933 & 0.910 \\
November & 1.31 & 0.774 & 0.771 & 1.29 & 0.774 & 0.771 & 1.25 & 0.772 & 0.771 \\
December & 1.44 & 0.807 & 0.803 & 1.43 & 0.807 & 0.803 & 1.39 & 0.806 & 0.802 \\
January (01) & 1.64 & 0.756 & 0.750 & 1.64 & 0.790 & 0.784 & 1.61 & 0.788 & 0.783 \\
12-month & 1.91 & 0.912 & 0.896 & 1.87 & 0.911 & 0.897 & 1.82 & 0.908 & 0.894 \\
\hline
\end{tabular}

Table 4-14 also shows a reduction in power variability between outputs from a single interconnection point Echo and the entire Lake Benton II wind power plant. This reduction in power variability is expected from large wind power plants with hundreds of wind turbines scattered over a wide area. The effect becomes more prominent when calculations are extended to the combined output of Storm Lake and Lake Benton II. Table 4-15 lists COVs of output power from four grid-interconnection points of Lake Benton II, Lake Benton II, Storm Lake, and combined Storm Lake and Lake Benton II output. Numbers in Table 4-15 are calculated with 1-second power data. As turbine output power becomes increasingly aggregated, the variability of the overall power level drops further. In the case of combined Storm Lake and Lake Benton II output, the result is a $20 \%$ reduction in power level variability. 
Table 4-15. Individual Grind-Interconnection Points and Wind Power Plant Output COVs

\begin{tabular}{llllllll}
\hline Month & Delta & Echo & Foxtrot & Golf & $\begin{array}{c}\text { Lake Benton } \\
\text { II }\end{array}$ & Storm Lake & Combined \\
\hline February & 0.800 & 0.777 & 0.824 & 0.766 & 0.773 & \\
March & 1.015 & 0.989 & 1.028 & 0.988 & 0.978 & \\
April & 0.835 & 0.823 & 0.876 & 0.842 & 0.815 \\
May & 1.009 & 1.008 & 1.159 & 0.935 & 0.922 \\
June & 0.852 & 0.838 & 0.867 & 0.927 & 0.845 & \\
July & 1.220 & 1.228 & 1.214 & 1.141 & 1.172 & \\
August & 0.933 & 0.918 & 0.905 & 0.909 & 0.899 & \\
September & 0.874 & 0.894 & 0.877 & 0.878 & 0.868 & \\
October & 0.979 & 0.936 & 0.917 & 0.919 & 0.911 & \\
November & 0.773 & 0.774 & 0.826 & 0.826 & 0.771 & 0.576 \\
December & 0.823 & 0.807 & 0.807 & 0.809 & 0.803 & 0.838 \\
January (01) & 0.753 & 0.756 & 0.757 & 0.756 & 0.750 & 0.829 \\
12-month & 0.921 & 0.909 & 0.937 & 0.909 & 0.893 & \\
February (01) & 0.733 & 0.743 & 0.740 & 0.740 & 0.728 & 0.834 \\
\hline
\end{tabular}




\section{Summary and Conclusions}

This is the first project in this country to monitor large wind power plant outputs by systematically collecting long-term, high-frequency data from large commercial wind power plants. Utilities, wind power plant developers, and operators need to understand the fluctuations in wind power and how they affect the electrical power system, as well as to analyze ancillary service requirements with real wind power plant output data. This project is designed to satisfy the need.

Over the past 13 months, more than 150 million data points have been collected and cataloged from two Midwest operating commercial wind power plants. Analysis of these data has provided useful insight on the behavior of wind power. This data set has been made available for Oak Ridge National Laboratory to investigate the ancillary service issues. It will also be available for others to study the operational impact issues of wind power plant on the utility power systems.

The first thing to notice from the collected data is that the actual magnitude of power fluctuations does not appear to be extraordinary. Changes of wind speed rarely cause extreme power-level changes of a large wind power plant. The variations in wind power plant output as a result of natural wind speed variations are well within the capability of an interconnected power system. When step changes are used to gauge the wind power fluctuations, changes appear small in value and are within a very narrow range. On a second-by-second basis, the maximum step changes are 4.4 MW up and 7.6 MW down; however, the standard deviation value $(\sigma)$ of all 1 -second step changes is only $168 \mathrm{~kW}$, with an average value of zero. Ninety-eight percent of all 1-second step change values are within $\pm 500 \mathrm{~kW}( \pm 3 \sigma)$, or less than $0.5 \%$ of total wind power plant generating capacity. The corresponding 1 -minute standard deviation value is 1,103 $\mathrm{kW}$ ( $1 \%$ of the total generating capacity), with $94.5 \%$ of the 1-minute step change values within $\pm 1,500$ $\mathrm{kW}( \pm 1.4 \sigma$ or $1.4 \%$ of total capacity).

The persistency of wind power from large plants is also evident in the state transition analysis of the output data. On a minute-by-minute basis, given the knowledge of current power output at any level (e.g., at $40 \%$ of the total capacity) operators can expect that at least $92 \%$ of the time, the output power will remain at the same level in the next minute. For shorter time steps, the probability of output power remains at the same level and is even higher at $94 \%$.

In addition to the limited range of power changes, the data show that the rates of power changes are also limited. For Lake Benton II, with 138 turbines and 103.5 MW of total capacity, the maximum ramping-up rate during a 10 -second period is $2.8 \mathrm{MW}$ per second and the maximum ramping down rate is $-2.5 \mathrm{MW}$ per second. The corresponding average ramping rates are only $28 \mathrm{~kW} / \mathrm{s}$ and $-31 \mathrm{~kW} / \mathrm{s}$. In a $10-$ minute window, the maximum ramping-up rate is $6.9 \mathrm{MW}$ per minute $(115 \mathrm{~kW} / \mathrm{s})$ and the maximum rampingdown rate is $6.6 \mathrm{MW}$ per minute $(110 \mathrm{~kW} / \mathrm{s})$. Both are much smaller than the 10 -second ramping rates. Furthermore, the distribution of ramp rates over the 12 -month period shows that $99 \%$ of the apparent power-changing rates are within $\pm 220 \mathrm{~kW} / \mathrm{s}$.

Actual wind power output data clearly show that spatial diversity plays a major role in reducing the variations of wind power plant output and peak power resulting from a wind gust. As expected, more wind turbines will tend to "smooth" the power output by reducing the variability of wind power.

The data also indicate the predictability of wind power plant output. Correlation analysis of power outputs from Lake Benton II and Storm Lake wind power plants shows that output from one plant can be a very good indication of output from the other plant. This suggests that, with adequate information about wind speed and direction (and other meteorological data) from strategically located places, one can predict output from a wind power plant with a reasonable degree of accuracy. 
These results also clearly indicate that while wind power plants will be subject to forced outages similar to those of any other power-generating plants, changes in power output resulting from changing winds are neither severe nor unpredictable.

With more analysis, we can further quantify the relationships between the outputs of several wind power plants, as well as determine whether sophisticated regression analyses can help wind power plant and utility system operators to better predict power output levels. Analysts will also attempt to correlate feed voltage at the grid-interconnection points. Furthermore, using real and reactive power data, they will seek to verify the advantages of reactive power control of wind turbines.

This is an ongoing project and should continue for another 2 years. Electrotek Concepts has begun collecting data at the Storm Lake plant and the Buffalo substation, an effort that should produce even more statistically significant conclusions. 
Public reporting burden for this collection of information is estimated to average 1 hour per response, including the time for reviewing instructions, searching existing data sources,

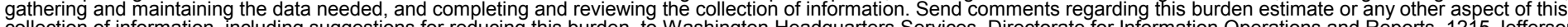
Davis Highway, Suite 1204, Arlington, VA 22202-4302, and to the Office of Management and Budget, Paperwork Reduction Project (0704-0188), Washington, DC 20503.

\begin{tabular}{|l|l|l|}
\hline 1. AGENCY USE ONLY (Leave blank) & $\begin{array}{l}\text { 2. REPORT DATE } \\
\text { July } 2001\end{array}$ & $\begin{array}{l}\text { 3. REPORT TYPE AND DATES COVERED } \\
\text { Technical Report }\end{array}$ \\
\hline
\end{tabular}

\begin{tabular}{l|l|l}
\hline 4. TITLE AND SUBTITLE & 5. FUNDING NUMBERS \\
Wind Power Plant Monitoring Project Annual Report &
\end{tabular}

\section{6. $\mathrm{AUTHOR}(\mathrm{S})$}

Yih-Huei Wan
7. PERFORMING ORGANIZATION NAME(S) AND ADDRESS(ES)

National Renewable Energy Laboratory

1617 Cole Blvd.

Golden, CO 80401-3393

9. SPONSORING/MONITORING AGENCY NAME(S) AND ADDRESS(ES)
WER13210

8. PERFORMING ORGANIZATION REPORT NUMBER TP-500-30032

10. SPONSORING/MONITORING AGENCY REPORT NUMBER

11. SUPPLEMENTARY NOTES

12a. DISTRIBUTION/AVAILABILITY STATEMENT

National Technical Information Service

U.S. Department of Commerce

5285 Port Royal Road

Springfield, VA 22161 12b. DISTRIBUTION CODE

13. ABSTRACT (Maximum 200 words)

The intermittent nature of the wind resource, together with short-term power fluctuations, are the two principal issues facing a utility with wind power plants in its power grid. To mitigate these issues, utilities, wind power plant developers, and operators need to understand the nature of wind power fluctuations and how they affect the electrical power system, as well as to analyze ancillary service requirements with real wind power plant output data. To provide the necessary data, NREL conducted a study to collect at least 2 years of long-term, high-frequency (1-hertz [Hz]) data from several mediumto large-scale wind power plants with different wind resources, terrain features, and turbine types. Researchers then analyzed the data for power fluctuations, frequency distribution of wind power (by deriving a probability distribution function of wind power plant output variations), spatial and temporal diversity of wind power, and wind power capacity credit issues. Results of these analyses can provide data on the potential effects of wind power plants on power system regulation.

14. SUBJECT TERMS wind power plants; utilities; ancillary services

15. NUMBER OF PAGES

17. SECURITY CLASSIFICATION OF REPORT Unclassified
18. SECURITY CLASSIFICATION OF THIS PAGE Unclassified
19. SECURITY CLASSIFICATION OF ABSTRACT Unclassified
16. PRICE CODE

20. LIMITATION OF ABSTRACT UL

NSN 7540-01-280-5500

Standard Form 298 (Rev. 2-89) Prescribed by ANSI Std. Z39-18 